بررسى تأثير زئوليت بر ضرايب مدلهاى منحنى رطوبتى خاك در دو بافت شنى و لومى

\author{
رضا قضاوى، ابراهيم اميدوار و حديثه جيحونى نايينى
}

(تاريخ دريافت:

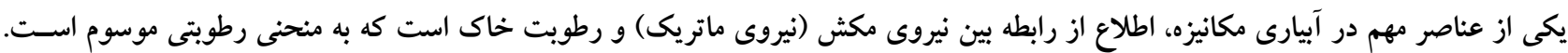

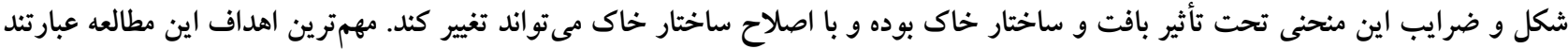

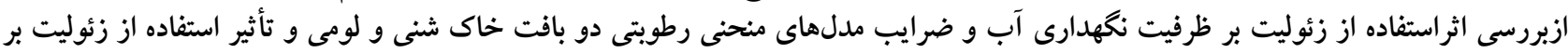

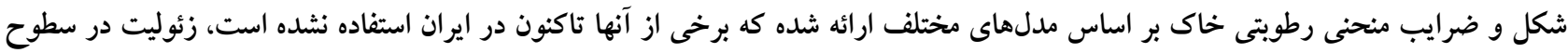

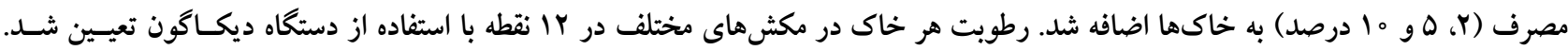

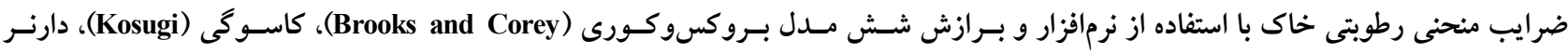

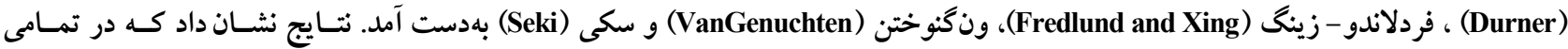

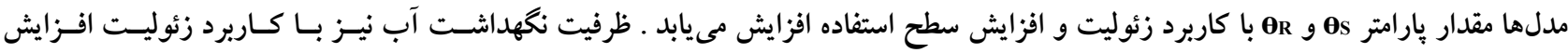

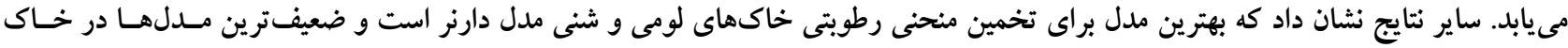

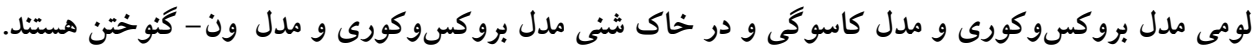

وازمهاى كليدى: زئوليت، منحنى رطوبتى خاك، نغهدارى آب در خاك و م/SWRC r. 
كه يتانسيل شيميايى آب در هيدروزل بالاتر از محيط باشد، نفوذ

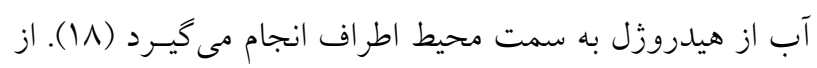
جمله اين سويرجاذب ها مى توان به كانىهاى زئوليت اشاره كرد.

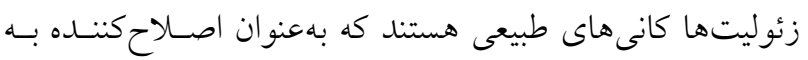

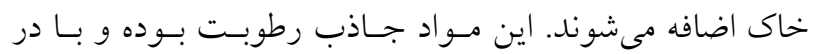

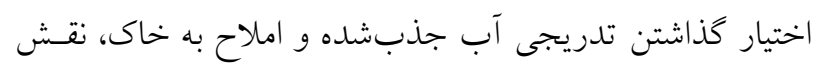
مهمى در حاصلخيزى خاك و جلو گيرى از هدررفتن آب دارند.

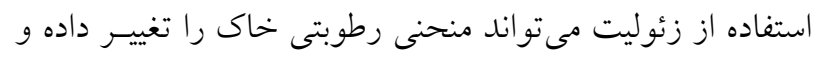
سبب افزايش نخهلارى رطوبت خاك شود (Y)).

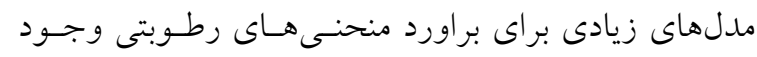
دارند كه شناخت بهتـرين منحنسى بـراى هـر خـاك در شـرايط مختلف مى تواند باعث افزايش دقت در براورد شـرايط رطـوبتى خاك شود. از طرفى نمـايش منحنسى رطوبتى بـهووسيله تـابع

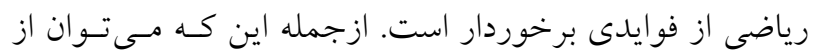

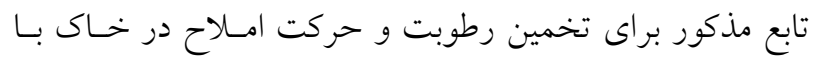

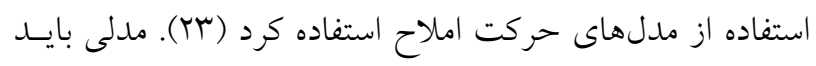

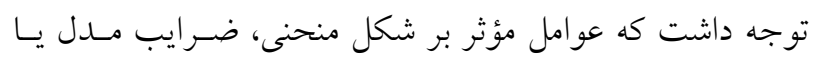

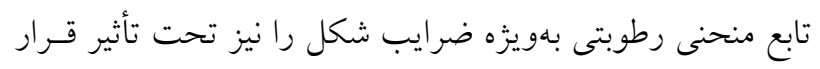

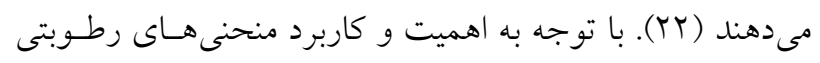
خاك، مطالعات متعددى در زمينه تعيين بهترين منحنى و كاربرد

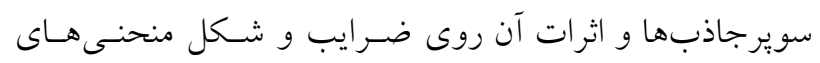

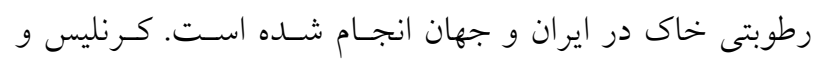
همكاران، طى مطالعهاى در زمينه منحنسى هــاى رطسوبتى، نتيجـهـ

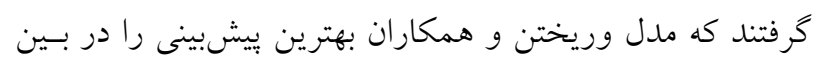

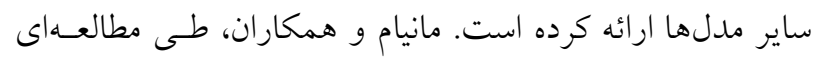

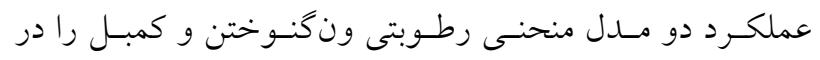

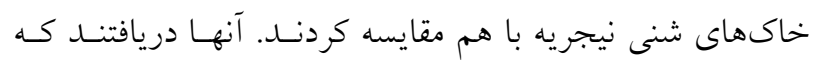

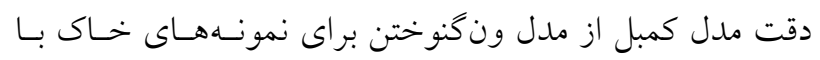

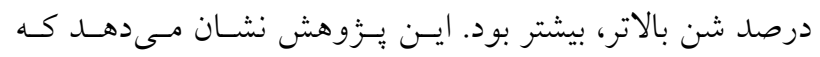

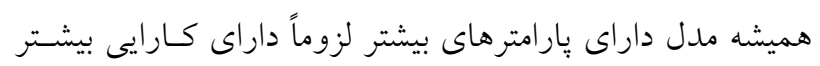

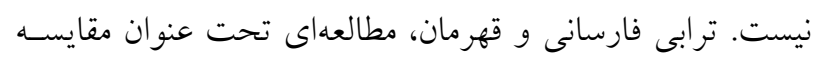

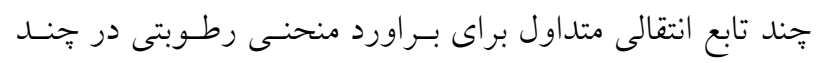

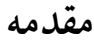

در مناطق خشك و نيمهخشـى مانـــــ اغلـب نقــاط ايـران، آب

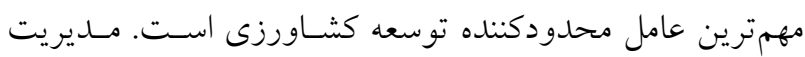

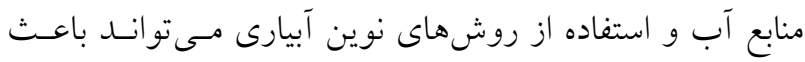

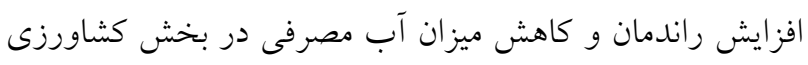

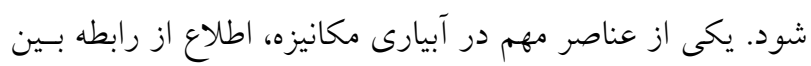

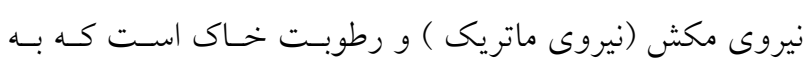

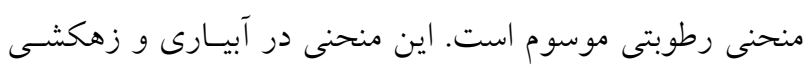

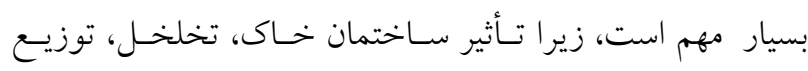
اندازه خللوفرج و جذب سطحى را بر حالت آب در خاك بيان

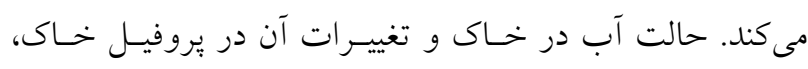

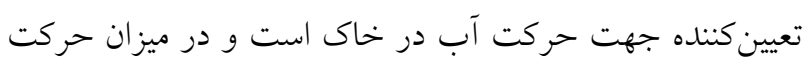

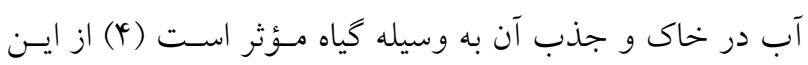
منحنى در بيشبينى ويزگكى هـاى هيـدروليكى خـاك و مسـائل

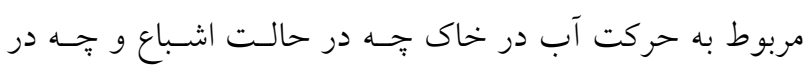

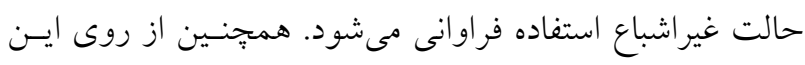

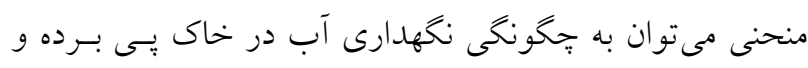

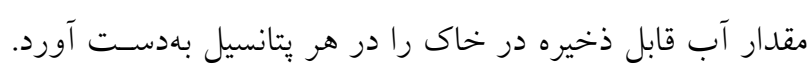

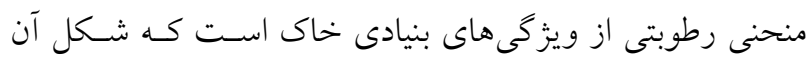

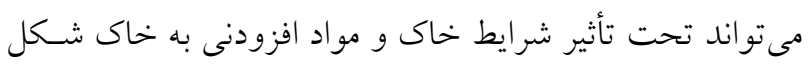

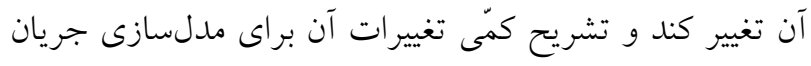

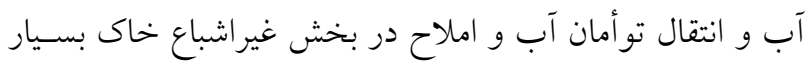

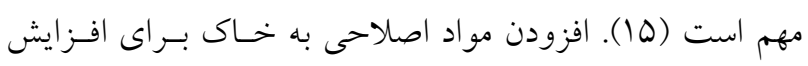

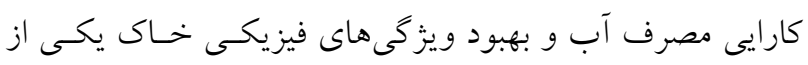

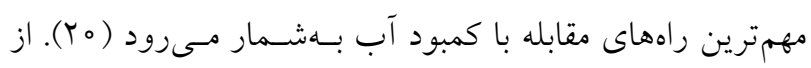

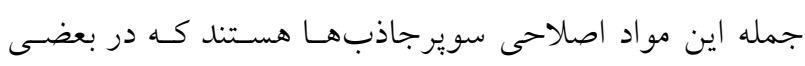

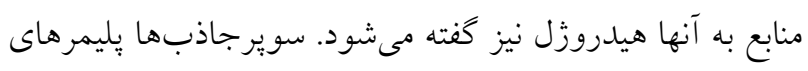

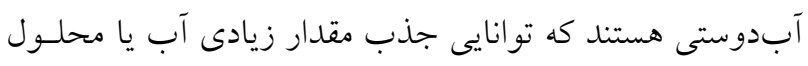

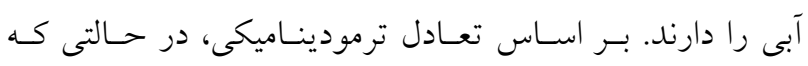

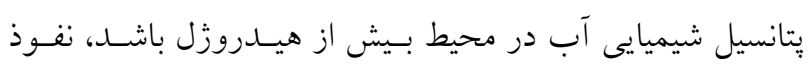

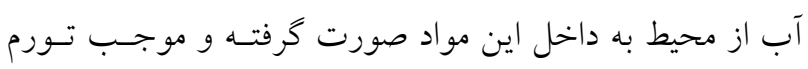

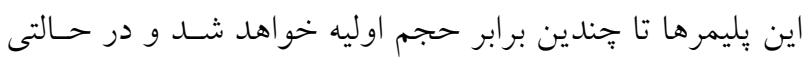


همجنِين با بررسى شاخص هاى آمـارى در مـدلهـاى كـاربردى

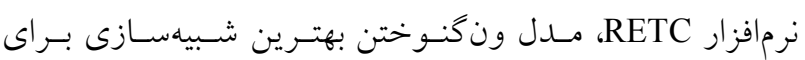

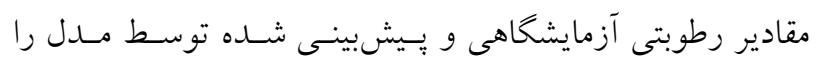

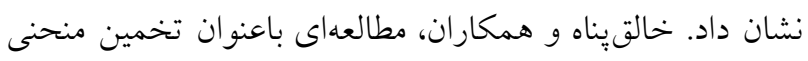
رطوبتى تعدادى از خاكهاى شور و شور و سديمى بـا استفاده

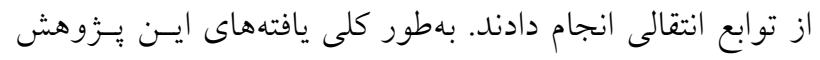

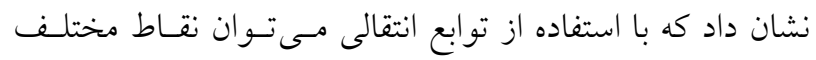

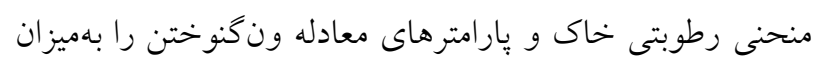
قابل قبولى تخمين زد.

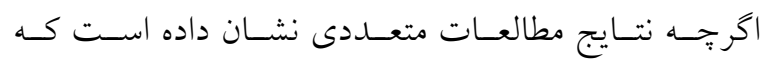

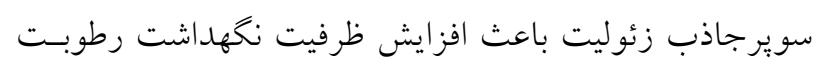

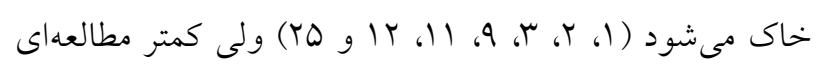

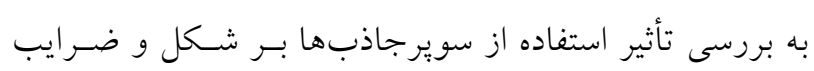

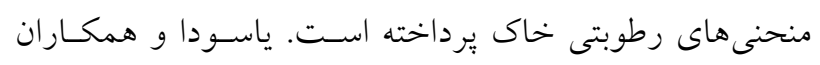

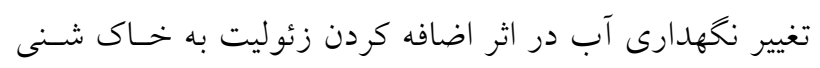

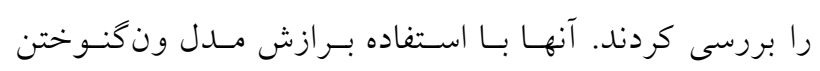

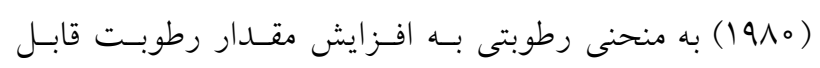

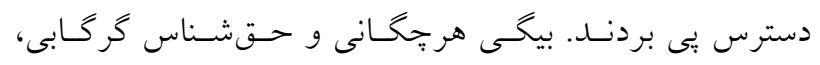

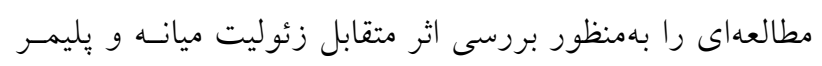

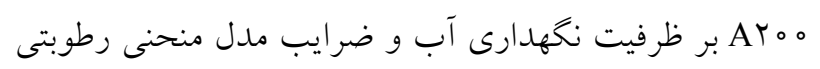

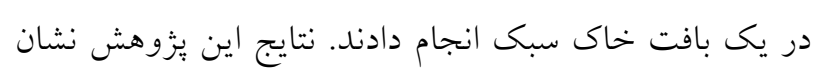

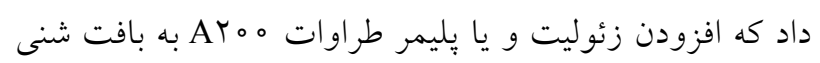

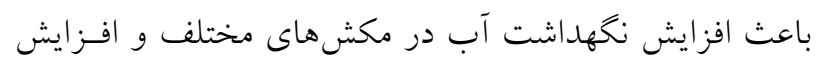

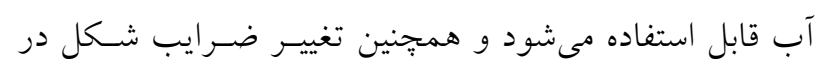

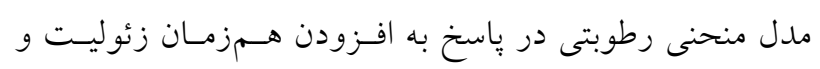

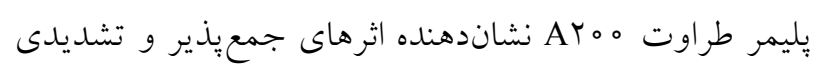

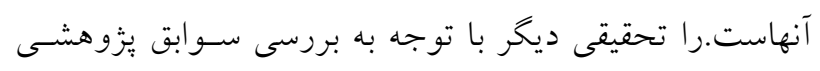

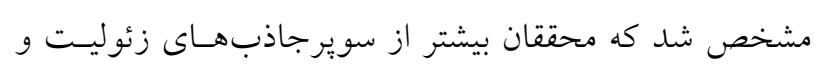
Aro。

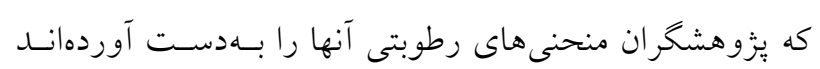

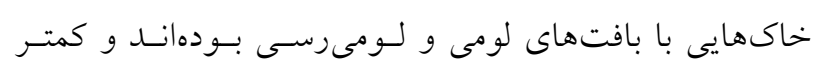

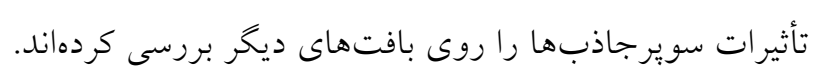

خاك در ايران انجام دادند. نتايج آنها نشان داد كه هـر دو مــدل

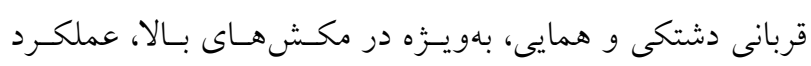

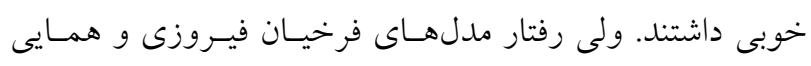

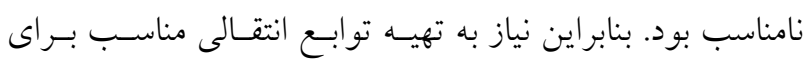

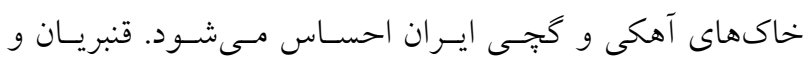

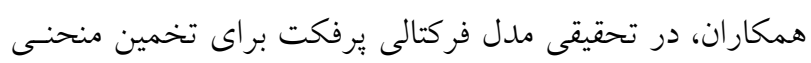

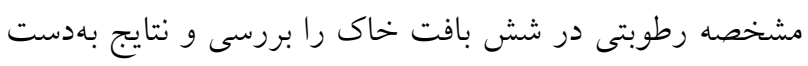

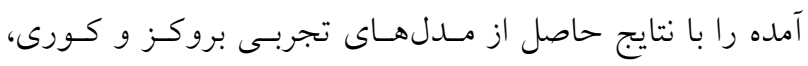

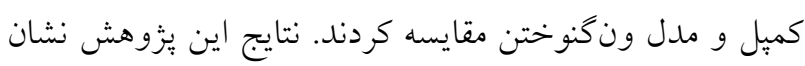

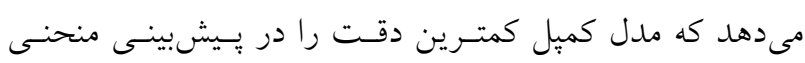

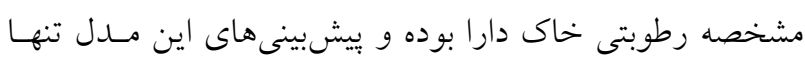

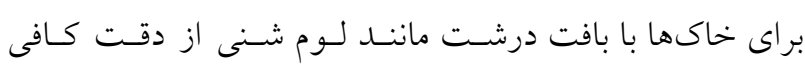

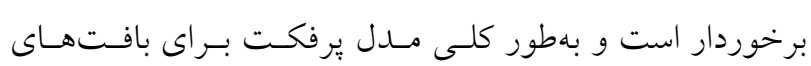

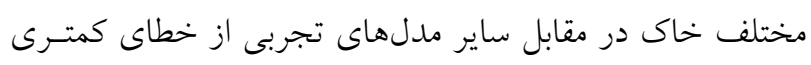
برخوردار بود. زارعى و همكاران، مطالعـهاى بــاعنسوان تخمسين

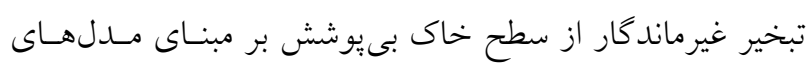

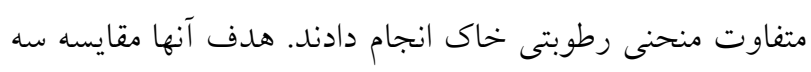

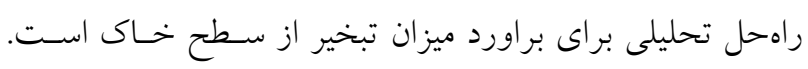

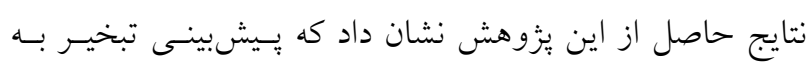
كمى مدل ونكنوختن بهتر از مدل بروكز -كورى بوده و استفاده

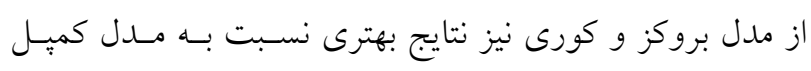

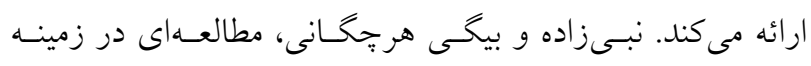

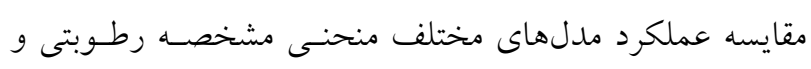

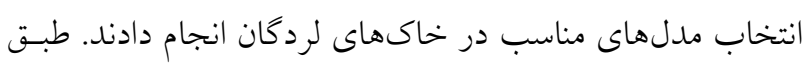

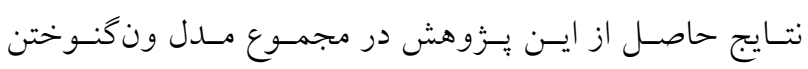

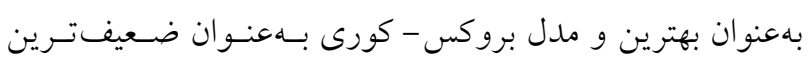

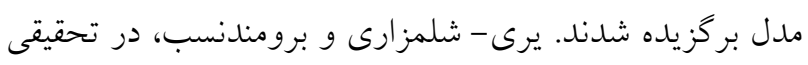

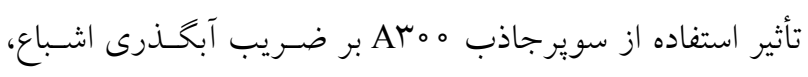

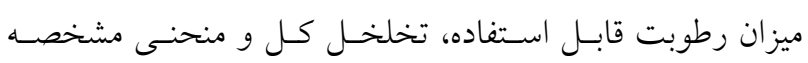

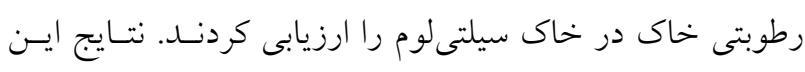

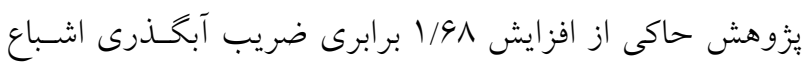

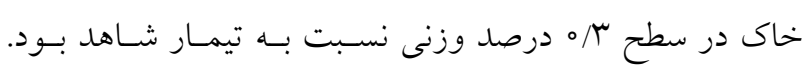


ديكاگون (مدل WPYC ساخت كشور آمريكا) استفاده شـد. بــ

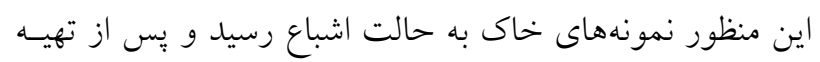

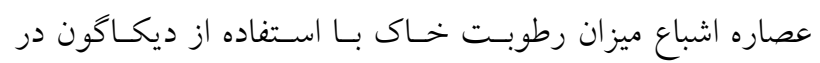

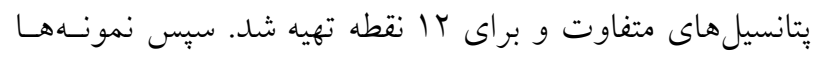

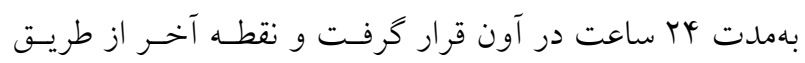

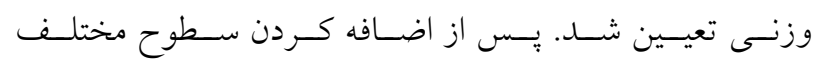

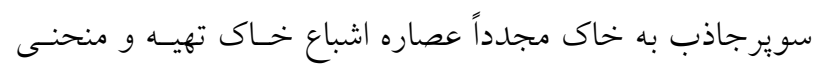

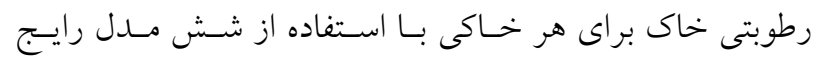

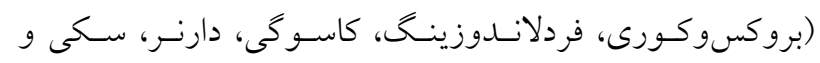
ون كنوختن) تهيه شد.

\section{آمادهازى خاى و بستر آزمايش}

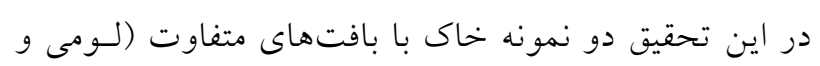

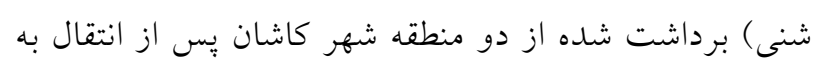

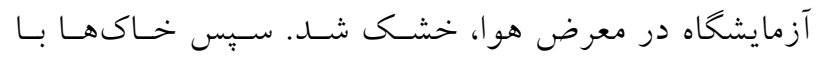

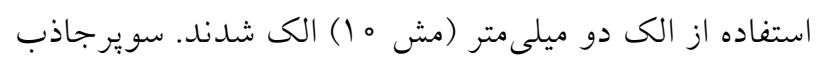

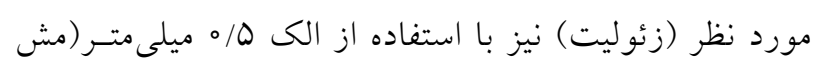

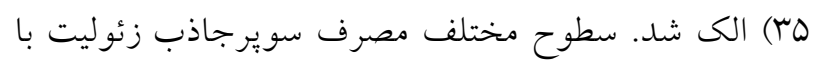

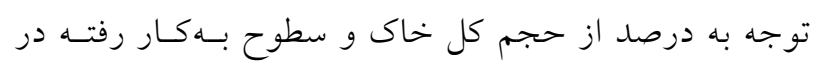

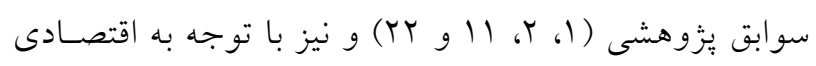
بودن افزايش زئوليت به خاك در سطوح صفر (بدون استفاده

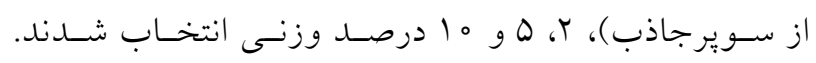

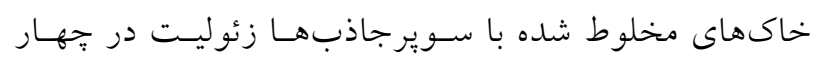
سطح درون ظرفهاى آزمايشخاهى ريخته و سبس كل كل اشباع

اندازهگيرى و محاسبه منحنى رطوبتى خاى

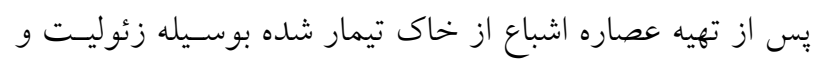

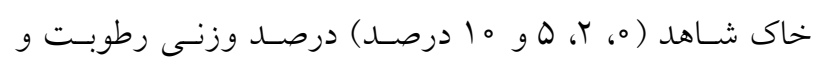

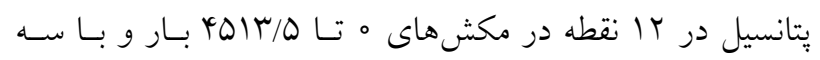

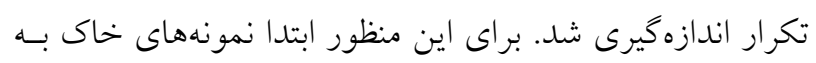

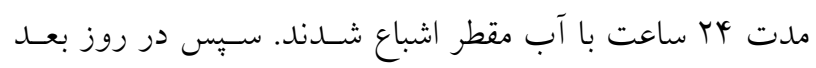

در مطالعات انجامشده بيشتر از مدلهاى ونكنوختن(1910) و

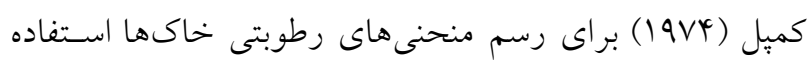

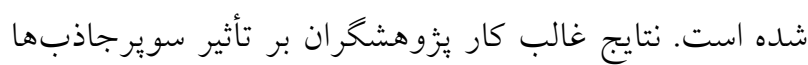

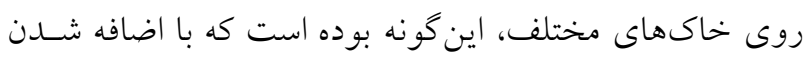

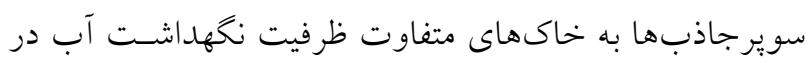

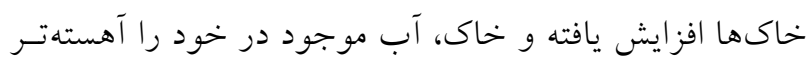

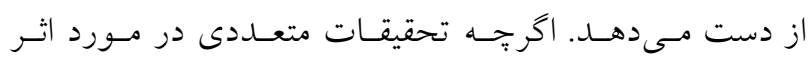

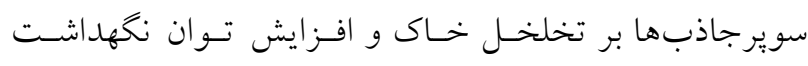

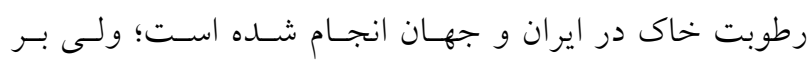

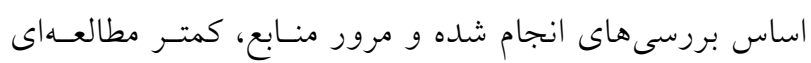

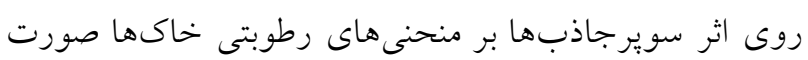

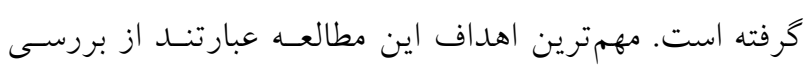

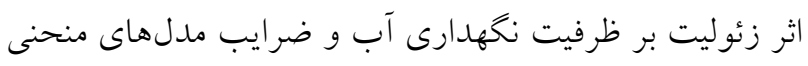

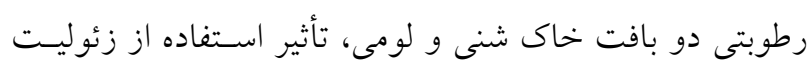

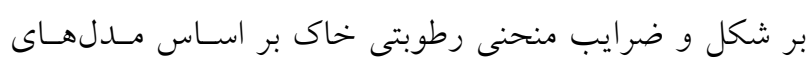

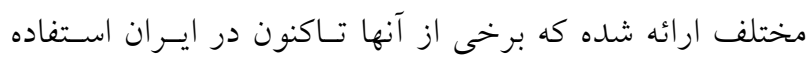

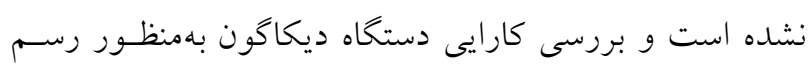

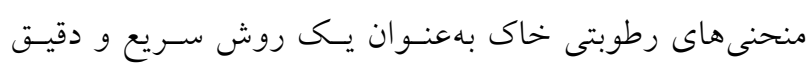

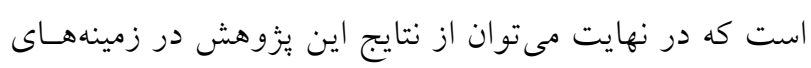

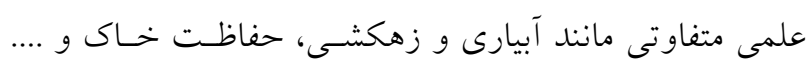

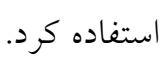

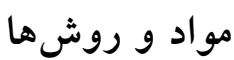
خاك و زئوليت مورد استفاده

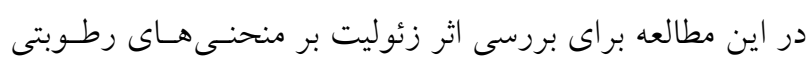

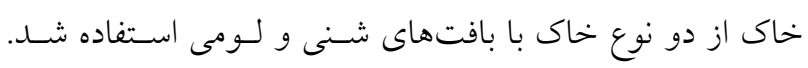

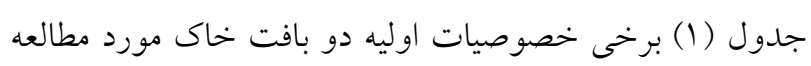

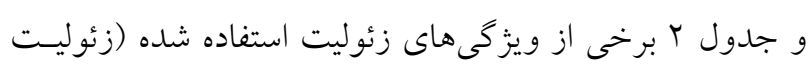

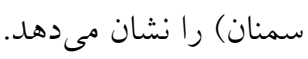

\section{روش انجام بزوهش}

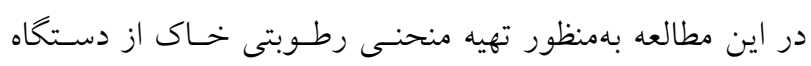


جدول ا. برخى ويزگى هاى اوليه دو بافت خاك مورد مطالعه

\begin{tabular}{|c|c|c|c|c|c|c|}
\hline $\mathrm{pH}$ & $(\mathrm{ms}) \mathrm{EC}$ & جِحالى ظاهرى( & شن (.) & سيلت (.٪) & رس (٪) & بافت خاى \\
\hline$V / 9 Y$ & $\mathrm{~V} / 11$ & $1 / 1 T Q$ & rV/AY & $\mu$ & $Y Y / L$ & 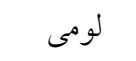 \\
\hline$V / q Y$ & $\circ / T V Y$ & $1 / \pi T G$ & $\wedge q / \wedge{ }^{4}$ & 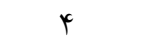 & $9 / 19$ & شنى \\
\hline
\end{tabular}

جدول r. برخى ويزّىىهاى سويرجاذب مورد مطالعه

\begin{tabular}{|c|c|c|c|c|c|c|c|c|c|}
\hline L.O.I & $\mathrm{SO}_{r}$ & $\mathrm{~K}_{\mathrm{r}} \mathrm{O}$ & $\mathrm{Na}_{\uparrow} \mathrm{O}$ & $\mathrm{MgO}$ & $\mathrm{CaO}$ & $\mathrm{Fe}_{r} \mathrm{O}_{r}$ & $\mathrm{Al}_{\digamma} \mathrm{O}_{\digamma}$ & $\mathrm{SiO}_{r}$ & مو اد تشكيل دهنده \\
\hline $10 / V Y$ & $0 / 091$ &.$/ 91$ &.$/ 90$ & $\circ / \sqrt{ } 9$ & Y/A & $\circ / 9 V$ & $11 / V^{4}$ & $9 \wedge / 90$ & $(\%)$ \\
\hline
\end{tabular}

تعيين مناسبترين مدل براورد منحنى رطوبتى خاك براى تعيين مناسبترين مـدل بـراورد منحنسى رطـوبتى خـاك از

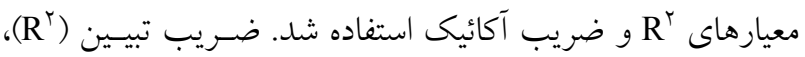
مجذور ضـريب همبسـتخى اسـت كـه ميـزان نزديكس دادهــاى شبيهسازى شد و مشاهدهشده را نشـان مسيدهـــ و بـا استففاده از رابطه (1) محاسبه مىشود. مقدار آن از صفر تا ا+متغير است كه

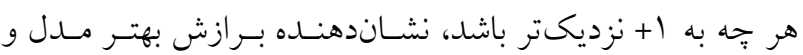

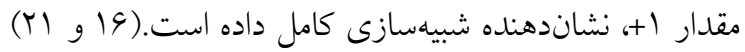

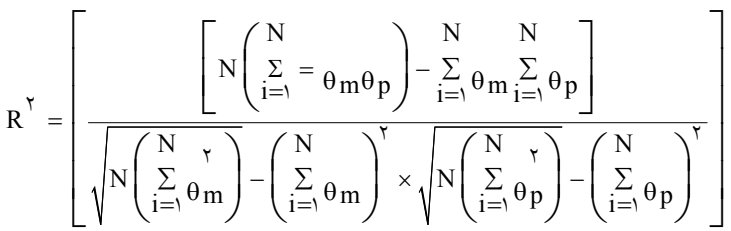
ضريب آكائيك(AIC)، معيار اطلاعات آكائيى است كه در سـال

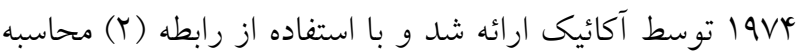

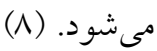

$$
\operatorname{AIC}=N \operatorname{NLn}\left(\frac{\Sigma\left({ }_{\theta_{p}}-\theta_{m}\right)^{r}}{N}\right)+r q
$$

معيارهاى R و ضريب آكائيكى بـراى تمـامى مــلـهـا در تمـامى بافتها و سطوح مختلف سويرجاذب محاسبه شد. سبس با استفاده

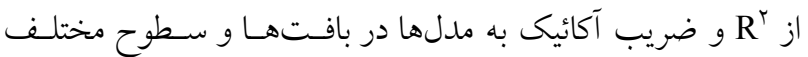
سويرجاذبها رتبههايى از يك تا شش داده شـــبدين صـورت كـهـ

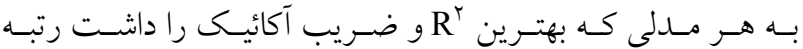

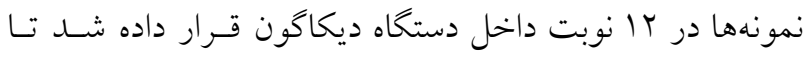

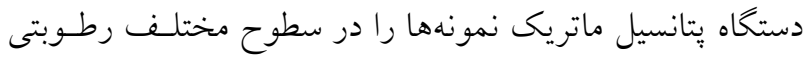

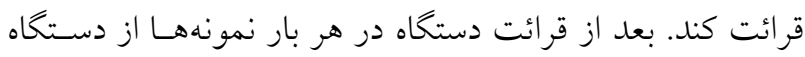

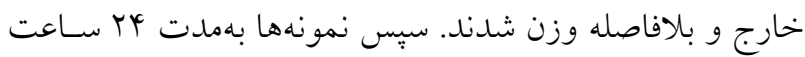

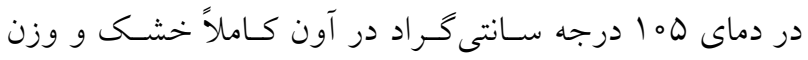
نهايى آنها نيز اندازهكيرى شد. فرانه اين اندازهگيرىها در طى يكى شبانهروز سـهـ بـار بـهـ فاصـله

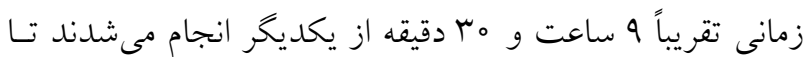
در طى جهار روز rا انقطه مشاهداتى بهدست بيايند.

\section{مدلهاى براورد منحنى رطوبتى خاك} بمنظور بررسى اثر كاربرد زئوليت بر شكل و ضرايب منحنى رطوبتى خاك از شش مدل بروكسو كورى، كاسوكى، فردلاند

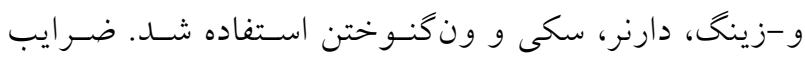

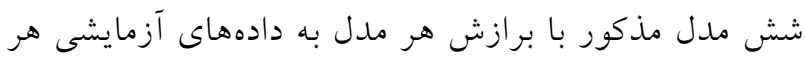

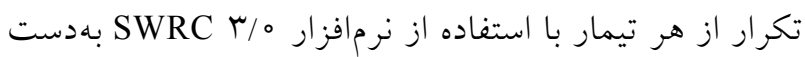

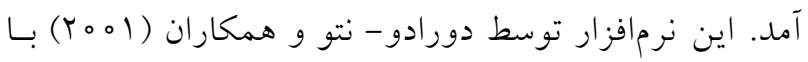

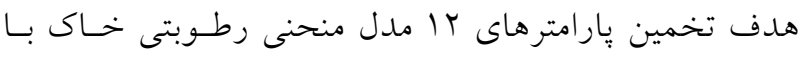

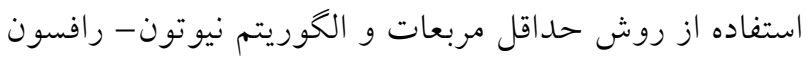

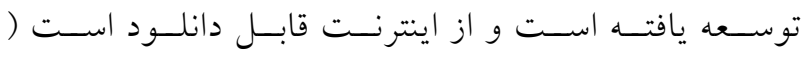
(http://purl.org/net/swrc (1) ). جدول ץ رابطههـاى شـش مدل بر اورد منحنى هاى رطوبتى خاك را نشان مىدهد. 
جدول r. رابطه هاى شش مدل براورد منحنى هاى رطوبتى خاك

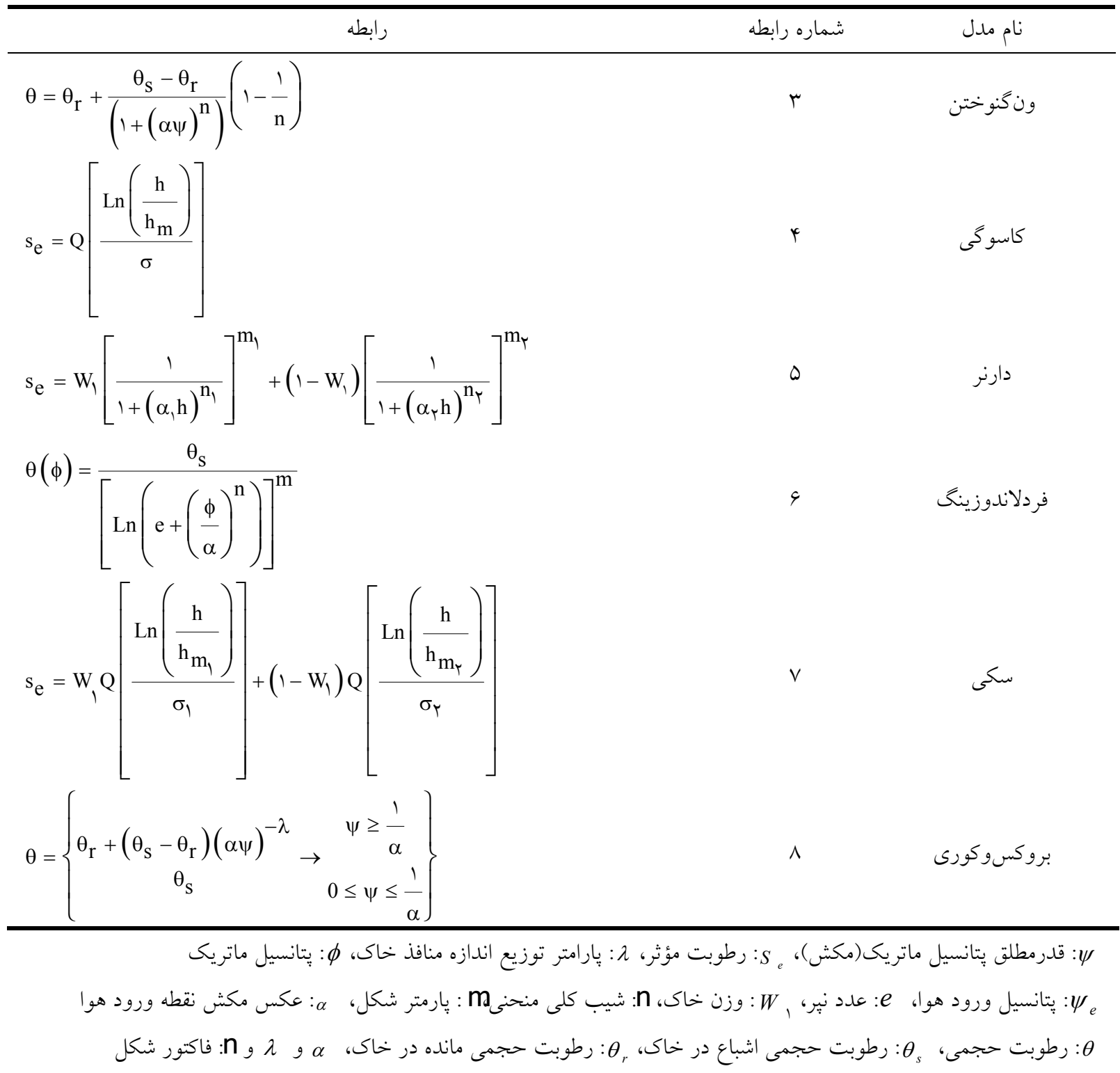

مصرف سوير جاذب مورد بحث قرار كرفته و دلايسل ايسن رونـدهــا

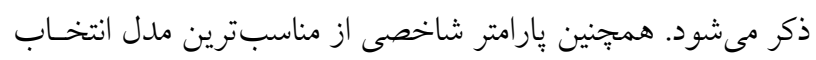

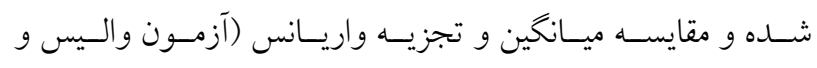

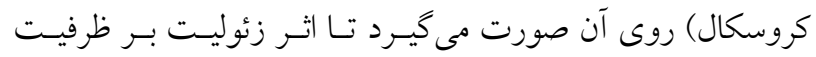
نخهارى آب در خاى بررسى شود.

\section{نتايج}

\section{منحنىهاى رطوبتى مشاهداتى}

نتايج نشان داد كه اضافه كردن سويرجاذب زئونئي
يك و هر مدلى كه بدترين R و ضريب آكائيك را داشت رتبه

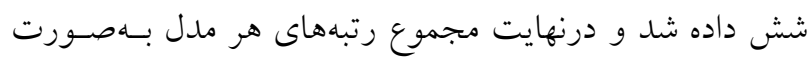

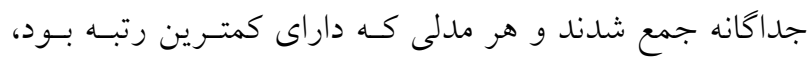
به عنوان مناسبترين مدل معرفى مىشود.

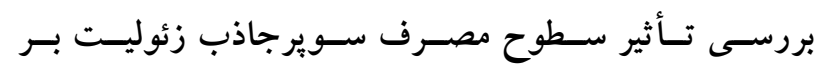

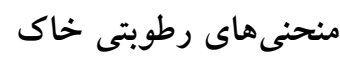

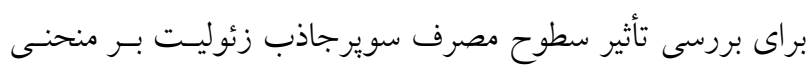

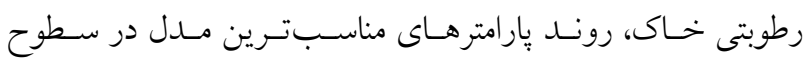



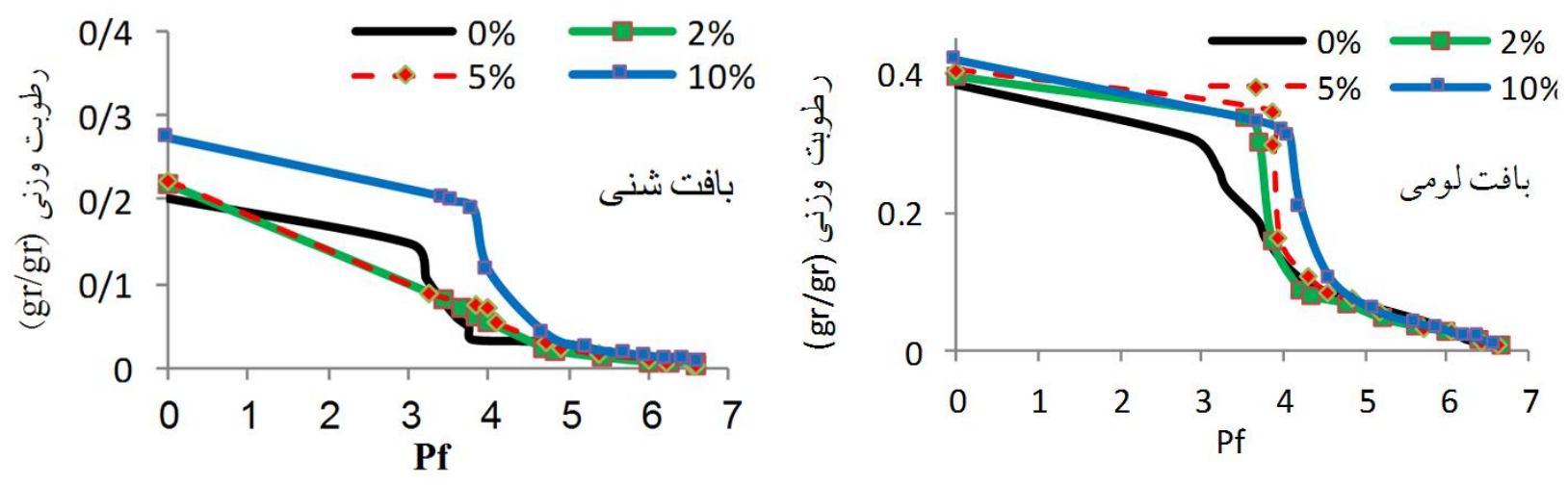

شكل 1. اثر كاربرد سويرجاذب زئوليت بر منحنىهاى رطوبتى دو نوع بافت خاك

افزايش نخهداشت آب بهواسطه وجود زئوليت در خاك اتفاق

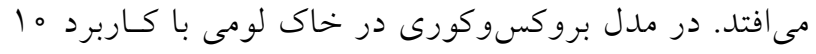
درصدى زئوليت مقدار ג كاهش يافت. كـاهش ايـن بــارامتر نشانه افزايش خللوفرج ريز بوده و افزايش خللوفنـرج ريـز

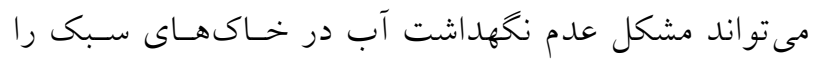

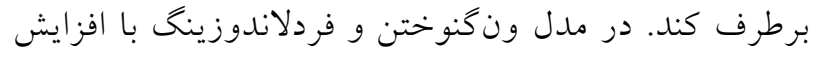

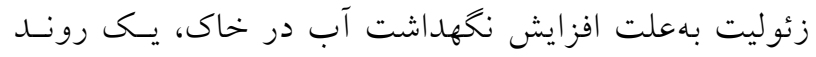

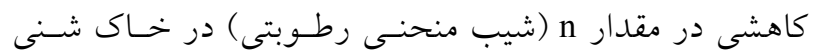

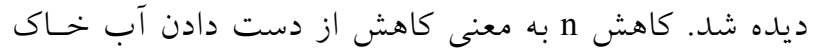

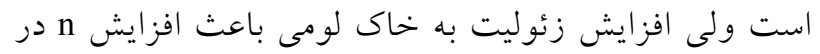

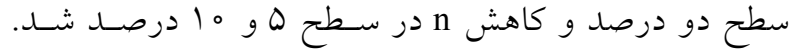

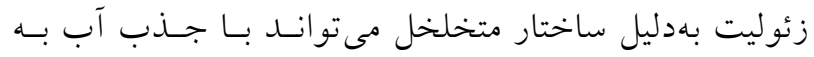

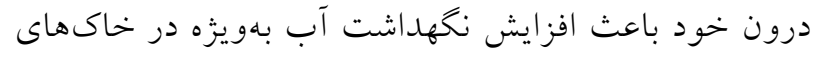
شنى شود. اين در حالى است كه در خاكهاى سنخين (شنى) n مقدار كمترى نسبت بـه بافـتهـاى سـبك دارد. در مـدل

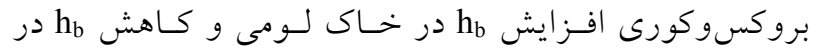
خاك شنى نشاندهنده به.بود ساختار رطوبتى خاك است.

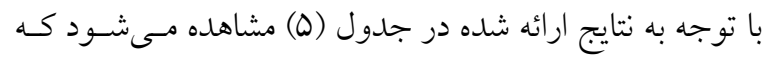

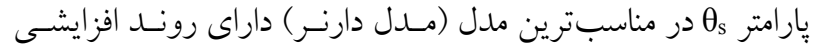
است به صورتى كه با افزايش سطوح مصرف سويرجاذب زئوليـت اين يارامتر نيز در هر دو بافت خاك افزايش مىيابد و ايسن افزايش

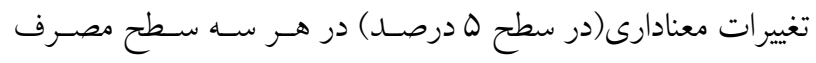

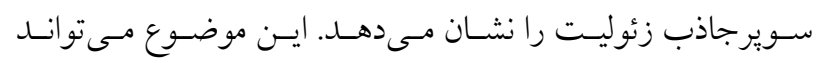
نشاندهنده افزايش ظرفيت نخهدارى آب در خاك با وجود زئوليت
مختلف به خاكهاى لومى و شـنى باعـث افـزايش رطوبـت

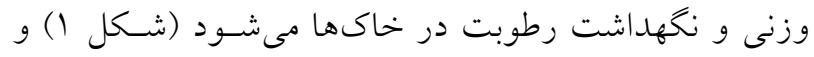
هرجه سطح مصرف سويرجاذبها افزايش مى يابد، رطوبـت وزنى و نخهداشت رطوبت در خاكها نيز افزايش مى يابد. بر

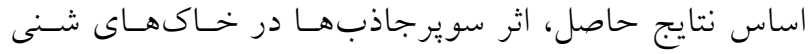

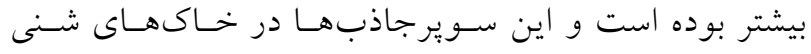

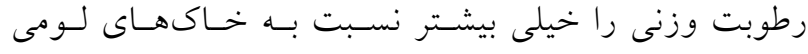
افزايش مىدهند و در نتيجه كارايى بالاترى را در خاكهـاى

شنى دارا هستند (شكل ()).

بررسـى تسأثير سـويرجاذب زئوليـت بــر ضــايب و شـكل منحنى هاى رطوبتى

بر اساس نتايج حاصل از بررسى اثر سوير جاذب زئب زئوليت بر مائ

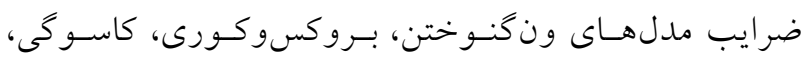
سكى، فردلاندوزينگ و دارنر مقدار

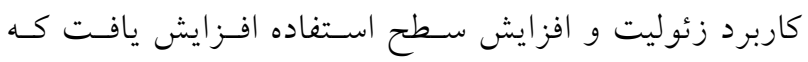

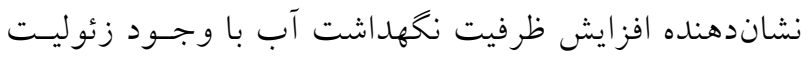

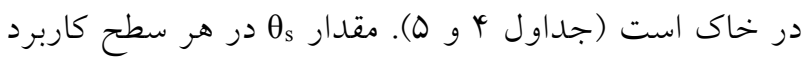

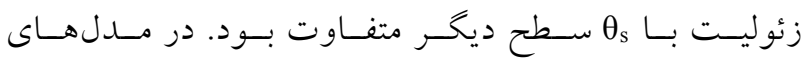

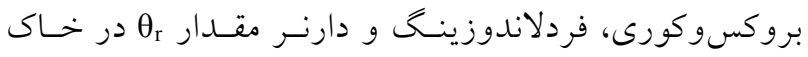

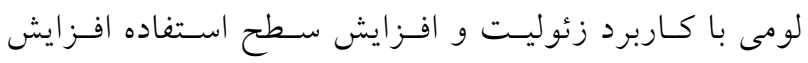

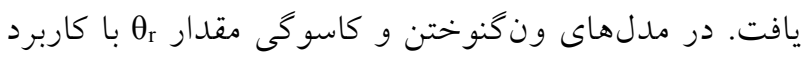
زئوليت در خاك لومى افزايش يافت ولى افزايش

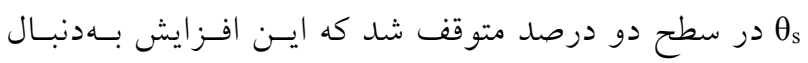


جدول f. مشخصات يار امترهاى معادلات بروكسوكورى، ون گنوختن، كاسو

\begin{tabular}{|c|c|c|c|c|c|c|}
\hline \multicolumn{4}{|c|}{ سطح كاربرد زئوليت (.) } & \multirow{2}{*}{ ضر ايب مدل } & \multirow{2}{*}{ بافت خاى } & \multirow{2}{*}{ 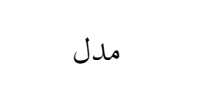 } \\
\hline 10 & 0 & r & $\circ$ & & & \\
\hline $0 / 41$ & $\circ / Y_{0}$ & $\circ / 4 q$ & $\circ / \mathrm{r}$ & $\theta_{\mathrm{s}}$ & \multirow{4}{*}{ خاى لومى } & \multirow{8}{*}{ برو كسو كورى } \\
\hline$r, 90 \mathrm{e}-\circ V$ & $\% / 0 \varphi^{r}$ & $\circ / 0 Y$ & $9,94 \mathrm{e}-09$ & $\theta_{\mathrm{r}}$ & & \\
\hline PDT/Ol & $90 \mathrm{r} / 99$ & MTY/lV & Tr/OV & $\mathrm{h}_{\mathrm{b}}$ & & \\
\hline.$/ 49$ & $r / 4 Q$ & $1 / \circ \mu$ & $\circ / T Q$ & $\lambda$ & & \\
\hline$\circ / T V$ & $0 / Y Y$ & $0 / T_{1}$ & $\circ / Y_{0}$ & $\theta_{\mathrm{s}}$ & \multirow{4}{*}{ خاك شنى } & \\
\hline $1,09 e-.99$ & $1,4 \wedge \mathrm{e}-09$ & $\wedge, \uparrow \circ \mathrm{e}-\circ \wedge$ & $0 / 01$ & $\theta_{\mathrm{r}}$ & & \\
\hline $19 V / 9 \Lambda$ & Tr/Vo & $r / / T_{G}$ & $99 / 79$ & $\mathrm{~h}_{\mathrm{b}}$ & & \\
\hline $0 / 49$ & $0 / \mu y$ & $\circ M V$ & $\circ / \wedge 1$ & $\lambda$ & & \\
\hline$\circ / 4 \circ$ & 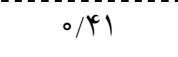 & $0 / 4 \circ$ & $0 / 49$ & $\theta_{\mathrm{s}}$ & \multirow{5}{*}{ خاى لومى } & \multirow{8}{*}{ ون گنوختن } \\
\hline $0 / 0 Y$ & $\circ / \circ r$ & 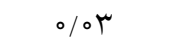 & $r, \circ 90 \mathrm{e}-\circ 9$ & $\theta_{\mathrm{r}}$ & & \\
\hline$q, Y l e-\circ r$ & $0 / 001$ & O००Y & $0 / 01$ & $\alpha$ & & \\
\hline$r / \circ 9$ & $r / 91$ & T/AY & $1 / r \omega$ & $\mathrm{n}$ & & \\
\hline $0 / T 9$ & $\circ / T r$ & $0 / T_{1}$ & $\circ / Y_{0}$ & $\theta_{\mathrm{s}}$ & & \\
\hline$\circ / \circ \circ D$ & $4, \circ 01 \mathrm{e}-\circ \wedge$ & $r, \vee \backslash \vee \mathrm{e}-\circ \wedge$ & $0 / 01$ & $\theta_{\mathrm{r}}$ & \multirow{3}{*}{ خاك شنى } & \\
\hline$\circ \% \circ Y$ & $\circ / \circ \Delta$ & 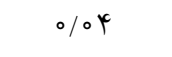 & $\circ / 0 \circ 9$ & $\alpha$ & & \\
\hline $1 / N r$ & $1 / \mu r$ & $1 / \% q$ & $Y / 09$ & $\mathrm{n}$ & & \\
\hline $0 / 41$ & $0 / 41$ & $\circ / 40$ & $\circ / \Lambda$ & $\theta_{\mathrm{s}}$ & \multirow{4}{*}{ خاى لومى } & \multirow{8}{*}{ كاسو گى } \\
\hline ०० r & $\circ / \circ$ & $\circ / \circ$ & $0 / 01$ & $\theta_{\mathrm{r}}$ & & \\
\hline $\mid V m a / 1$ & $909 / 09$ & $991 / \mu^{\circ}$ & ॠAG/DQ & $\mathrm{h}_{\mathrm{m}}$ & & \\
\hline yor & $\circ / N$ & $0 / 99$ & $r / 09$ & $\sigma$ & & \\
\hline$\circ / T V$ & $\circ / T Q$ & $\circ / T Y$ & $\circ / Y_{\circ}$ & $\theta_{\mathrm{s}}$ & \multirow{4}{*}{ خاك شنى } & \\
\hline $0 / 01$ & $q, 0 \circ 9 \mathrm{e}-\circ \psi^{q}$ & ०/०० & $0 / 01$ & $\theta_{\mathrm{r}}$ & & \\
\hline$\Lambda F \mid / 9 V$ & $\vee \wedge$ & $49 \pi \wedge$ & $\mid V \Lambda / \Delta \Lambda$ & $\mathrm{h}_{\mathrm{m}}$ & & \\
\hline $1 / 41$ & $r / 90$ & $r / r \mu$ & $1 / 09$ & $\sigma$ & & \\
\hline$\circ / 4 \circ$ & $0 / 41$ & $\circ / 4 q$ & $\circ / 4 q$ & $\theta_{\mathrm{s}}$ & \multirow{6}{*}{ خاى لومى } & \multirow{10}{*}{ فردلاند - زينگ } \\
\hline $0 / 01$ & $0 / 009$ & $\varphi, \Gamma \wedge l e-\circ \varphi$ &.$/ 01$ & $\theta_{\mathrm{r}}$ & & \\
\hline$|K| N / D$ & $G \mid r / \Delta Y$ & KKYT/Y & $10 \wedge F / V$ & $\mathrm{a}$ & & \\
\hline $1 / 00$ & $1 / 14$ & $\circ / \mathrm{VV}$ & $r / \circ r$ & $\mathrm{~m}$ & & \\
\hline $1 / 91$ & $T / Y_{\Lambda} \Lambda$ & $0 / 01$ & $\circ / \Delta r$ & $\mathrm{n}$ & & \\
\hline$\circ / T V$ & $\circ / T Y$ & $\circ / Y \wedge$ & $\circ / T_{0}$ & $\theta_{\mathrm{s}}$ & & \\
\hline$\circ / \circ \circ \Delta$ & $1, x^{\mathrm{c}} \wedge \mathrm{e}-\circ \psi^{\mathrm{c}}$ & ०/००ץ & r,199e-०9 & $\theta_{\mathrm{r}}$ & \multirow{4}{*}{ خاك شنى } & \\
\hline VMT/90 & $11 \circ / \mathrm{VA}$ & rVYV/G & $q V / T \circ$ & $\mathrm{a}$ & & \\
\hline$T / T)$ & T/VI & $\Lambda / \Lambda \mu$ & $1 / 00$ & $\mathrm{~m}$ & & \\
\hline $1 / 19$ & $0 / 4 y$ & $\circ / \mu_{0}$ & $T / T Q$ & $\mathrm{n}$ & & \\
\hline
\end{tabular}


جدول ه. مشخصات يارامترهاى معادلات دارنر و سكى

\begin{tabular}{|c|c|c|c|c|c|c|}
\hline \multicolumn{4}{|c|}{ سطح كاربرد زئوليت (.) } & \multirow{2}{*}{ ضر ايب مدل } & \multirow{2}{*}{ بافت خاى } & \multirow{2}{*}{ ملدل } \\
\hline 10 & 0 & r & 。 & & & \\
\hline $0 / 41$ & $\circ / \mathcal{C}_{0}$ & $0 / \pi q$ & $0 / 41$ & $\theta \mathrm{s}$ & \multirow{8}{*}{ خاى لومى } & \multirow{14}{*}{ دارنر } \\
\hline$\wedge, q \circ e-\circ \vee$ & $1,1 \circ e-\circ \Delta$ & $\varphi, \varphi \mid e-\circ V$ & $v, 9 \mid e-09$ & $\theta \mathrm{r}$ & & \\
\hline$\circ / \Lambda$ & $\circ / \mathrm{V}$ & $0 / 49$ & $0 / 44$ & $\mathrm{w}_{1}$ & & \\
\hline 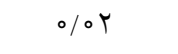 & $0 / 001$ & $0 / 004$ & $1 / 91$ & $\alpha_{1}$ & & \\
\hline $1 / r_{0}$ & $1 \% / 19$ & $|/ \mu| Y$ & $1 / r_{0}$ & $\mathrm{n}_{1}$ & & \\
\hline$\varphi, r \circ e-\circ \varphi^{c}$ & $r, \vee 9 e-\circ \varphi^{r}$ & $0 / 001$ & \%०० & $\alpha_{Y}$ & & \\
\hline$r / \mu$ & $1 / \kappa_{0}$ & $10 / 41$ & $1 / 90$ & $\mathrm{n}_{\Upsilon}$ & & \\
\hline $0 / T V$ & $0 / T r$ & $0 / T_{1}$ & $\circ / r_{0}$ & $\theta$ s & & \\
\hline$r, \wedge \& \mu_{e}-\circ V$ & $\circ / 0 \circ Y$ & \%०० & $r, \boldsymbol{r}$ le $e-\circ \mathrm{V}$ & $\theta \mathrm{r}$ & \multirow{6}{*}{ خاك شنى } & \\
\hline $0 / 90$ & $\circ / \Delta \Delta$ & $0 / 94$ & $0 / T Y$ & $w_{1}$ & & \\
\hline $0 / 01$ & $0 / 009$ & $\circ / \circ \circ Y^{f}$ & $0 / 009$ & $\alpha_{1}$ & & \\
\hline $1 / 149$ & $r Q / 19$ & $I V / \Delta D$ & $1 / 19$ & $\mathrm{n}_{1}$ & & \\
\hline$\circ / 001$ & $\circ / 001$ & $\circ / 001$ & $0 / 009$ & $\alpha_{Y}$ & & \\
\hline $\mathrm{rV} / 01$ & $1 / \Delta \wedge$ & $1 / 09$ & $r / D 1$ & $\mathrm{n}_{\mathrm{Y}}$ & & \\
\hline OMY & $\circ / 40$ & $\circ / 4 q$ &.$/ 49$ & $\theta \mathrm{s}$ & \multirow{7}{*}{ خاك لومى } & \\
\hline$\circ / \circ$ & $0 / 009$ & $\Delta, \uparrow \backslash \vee e-\circ \wedge$ & $0 / 01$ & $\theta \mathrm{r}$ & & \\
\hline$\circ / \mu$ &.$/ 90$ & $\circ / \Delta \Delta$ & $\circ / \mu 1$ & $w_{1}$ & & \\
\hline$Y G Y / Q Y$ & $V V D / \mu I$ & $q \mu / \Delta D$ &.$/ 90$ & $\mathrm{hm}_{1}$ & & \\
\hline$\circ / \mathrm{V}$ & $\circ / 11$ & $\circ / \mathrm{V}$ & $O / T Y$ & $\sigma_{1}$ & & \\
\hline 1945 & $\vee \backslash \wedge V$ & IEYN/V & GYY/OY & $\mathrm{hm}_{r}$ & & \\
\hline$\circ N Y$ & $T / M G$ & $r / 90$ & $1 / \wedge 1$ & $\sigma_{r}$ & & \\
\hline $0 / T V$ & $0 / Y r$ & $0 /$ TY & $0 / Y_{0}$ & $\theta \mathrm{s}$ & \multirow{7}{*}{ خاك شنى } & Gor \\
\hline$\circ / \circ \circ \mu$ & $\circ / \circ \circ Y^{c}$ & $1, \circ \Delta \psi^{r} e-\circ V$ &.$/ 01$ & $\theta \mathrm{r}$ & & \\
\hline$\circ / \Delta \wedge$ & $\circ / 0 \circ$ & $\circ / 10$ & $\circ / \Lambda \circ$ & $w_{1}$ & & \\
\hline TVN/YG & $1 / 900$ & $Y N / 0 D$ & $\mid M Y / Y \Lambda$ & $\mathrm{hm}_{1}$ & & \\
\hline$\Gamma / \Upsilon \Lambda$ & $\circ M{ }^{k}$ & $\wedge / 9 \wedge$ & $\circ / V Y$ & $\sigma_{1}$ & & \\
\hline $949 / 11$ & IYYY/I & $\vee Q / \wedge \varphi$ & $9 \circ+/ 99$ & $\mathrm{hm}_{r}$ & & \\
\hline$\circ / \circ \Delta$ & $1 / 91$ & $T / 9 V$ & $0 / 09$ & $\sigma_{Y}$ & & \\
\hline
\end{tabular}

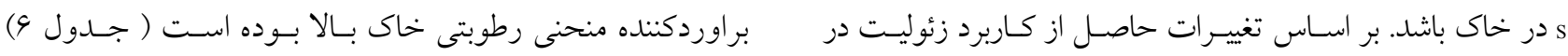

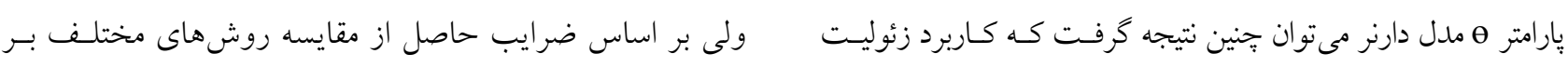

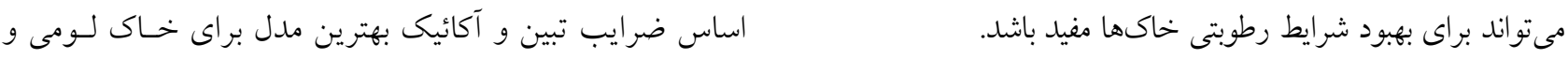

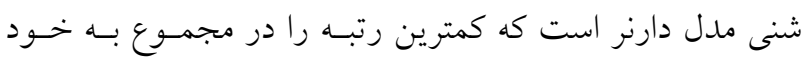

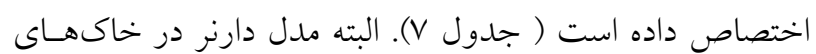
تعيين مناسبترين مدل براورد كننده منحنى رطوبتى

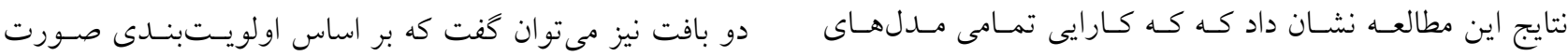


جدول 9. آمارههاى كيفيت برازش شش مدل منحنى رطوبتى خاى

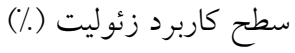

$10 \quad 0$

\begin{tabular}{|c|c|c|c|c|c|c|c|c|c|}
\hline AIC & $\mathrm{R}^{r}$ & AIC & $\mathrm{R}^{r}$ & AIC & $\mathrm{R}^{r}$ & AIC & $\mathrm{R}^{r}$ & & \\
\hline$-V Q / \Lambda I$ & $0 / 99$ & $-\vee Q / \circ \wedge$ &.$/ 90$ & $-\Lambda V / \mu r$ &.$/ 9 V$ & $-V / N / 9$ &.$/ 90$ & خاك لومى & \multirow{2}{*}{ بروكسو كورى } \\
\hline$-q V / F V$ & $0 / 91$ & $-119 / 94$ & $0 / 99$ & $-\mid r G / 40$ & $0 / 99$ & $-110 / 14$ & $0 / 99$ & خاك شنى & \\
\hline$-M / / \mu I$ & $0 / 91$ & $-V r / 9 \Lambda$ & $0 / 9 r$ & $-\lambda \psi / N I$ & $\circ / 9 \mathrm{~V}$ & $-9 r / 01$ &.$/ 91$ & خاك لومى & \multirow{2}{*}{ ونكنوختن } \\
\hline$-10 r / r r$ & $0 / 91$ & $-114 / \pi r$ &.$/ 91$ & $-\mid \kappa_{0} / r_{0}$ & $0 / 99$ & $-11 \% / N 0$ &.$/ 99$ & خاك شنى & \\
\hline$-\Lambda \varepsilon / q \psi$ & $0 / 91$ & $-V Y / D 1$ & ./9r & $-\wedge 1 / 9 V$ & $0 / 99$ & $-9 / / 10$ &.$/ 99$ & خاك لومى & \multirow{2}{*}{ كاسوگى } \\
\hline$-|0 Y / N|$ & $0 / 91$ & $-1 K G / V G$ & $0 / 99$ & $-1 \times q / 9 V$ & $0 / 99$ & $-111 \% / 0 \wedge$ &.$/ 91$ & خاك شنى & \\
\hline$-\wedge V / V Q$ & $0 / 91$ & $-V \Gamma / \Gamma \Delta$ &.$/ 94$ & $-9 Y / 91$ & $0 / 91$ & $-9 \Lambda / V Q$ & $0 / 99$ & خاك لومى & \multirow{2}{*}{ فردلاندوزينگ } \\
\hline$-10 \% / T r$ & $0 / 99$ & -||$N / N \mid$ & $0 / 99$ & $-\mid \Psi N / V \Lambda$ & $0 / 99$ & $-11 V / 11$ & $0 / 99$ & خاك شنى & \\
\hline$-\wedge Q / 9 r$ & $0 / 99$ & $-1 r_{0} / \varphi_{0}$ & $0 / 99$ & $-1 K \pi / 9 \pi$ & $0 / 99$ & $-1.4 / 04$ & $.0 / 99$ & خاك لومى & \multirow{2}{*}{ دارنر } \\
\hline$-|r q / 4|$ & $0 / 99$ & $-|r N / \cdot|$ & $0 / 99$ & $-\mid Q T / T V$ & $0 / 99$ & $-110 / \circ V$ &.$/ 99$ & خاك شنى & \\
\hline$-\lambda r / T_{G}$ & $0 / 91$ & $-1 r \circ / r q$ & $0 / 99$ & $-|r \Delta / v|$ & $0 / 99$ & $-99 / 09$ &.$/ 99$ & خاك لومى & \multirow{2}{*}{ سكى } \\
\hline$-\mid Y N / \circ r$ & $0 / 99$ & $-|T \Delta / \Delta|$ & $0 / 99$ & $-1 k \mu / q \pi$ & $0 / 99$ & $-1.9 / V 9$ & $0 / 99$ & خاك شنى & \\
\hline
\end{tabular}

جدول V. رتبهبندى شش مدل منحنى رطوبتى خاى در دو بافت خاى شنى و لومى

\begin{tabular}{|c|c|c|c|c|c|c|c|c|c|c|c|}
\hline \multirow[t]{2}{*}{ اولويت انتخاب } & \multirow{2}{*}{ مجموع رتبه مدل } & \multicolumn{4}{|c|}{ رتبه مدل در خاك شنى در كاربرد زئوليت (\%) } & \multirow{2}{*}{ مجموع رتبه مدل } & \multicolumn{4}{|c|}{ رتبه مدل در خاك لومى در كاربرد زئوليت (\%) } & \multirow[t]{2}{*}{ مدل } \\
\hline & & 10 & 0 & r & $\circ$ & & 10 & 0 & $r$ & $\circ$ & \\
\hline 4 & 19 & 9 & 0 & 9 & r & 19 & 4 & r & r & 9 & برو كسو كورى \\
\hline 0 & 19 & r & 9 & 0 & r & 19 & r & $\varphi$ & 0 & 0 & ون كنوختن \\
\hline t & r & r & r & r & $\Delta$ & 19 & r & 9 & 4 & r & كاسو گى \\
\hline r & ir & $\Delta$ & r & $r$ & 1 & 10 & r & 0 & r & r & فردلاندوزينگ \\
\hline 1 & V & r & 1 & 1 & $\mu$ & $\Delta$ & 1 & 1 & r & 1 & دارنر \\
\hline r & 14 & 1 & $r$ & c & 9 & 10 & 0 & r & 1 & r & سكى \\
\hline
\end{tabular}

و در هر دو بافت نيز مدل بروكسوكورى بيشـترين رتبـه را بـه

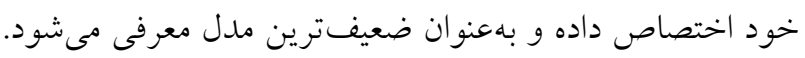

تأثير سطوح مصرف سـويرجاذب زئوليست بـر منحنسىهـاى رطوبتى خاى

با توجه به اين موضوع كه مـــل دارنــــــــــــوان بهتـرين مـدل

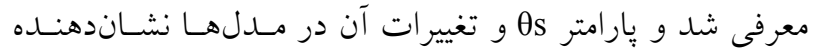

كرفته، مدل دارنر بهترين برازش را با دادههاى اندازهكيرى شــده داشته است ( جدول V) . يكى از دلايلى كه مدل دارنـر بهتـرين

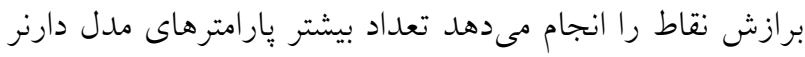

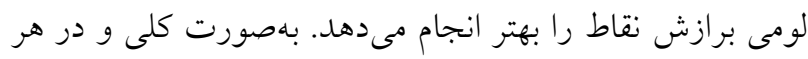

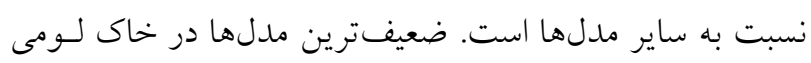

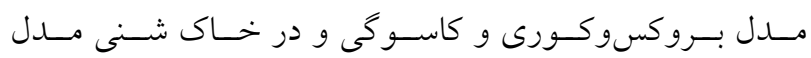
بروكسوكورى و ونكنوختن هستند (جدول V). بهصورت كلى الى درولي 

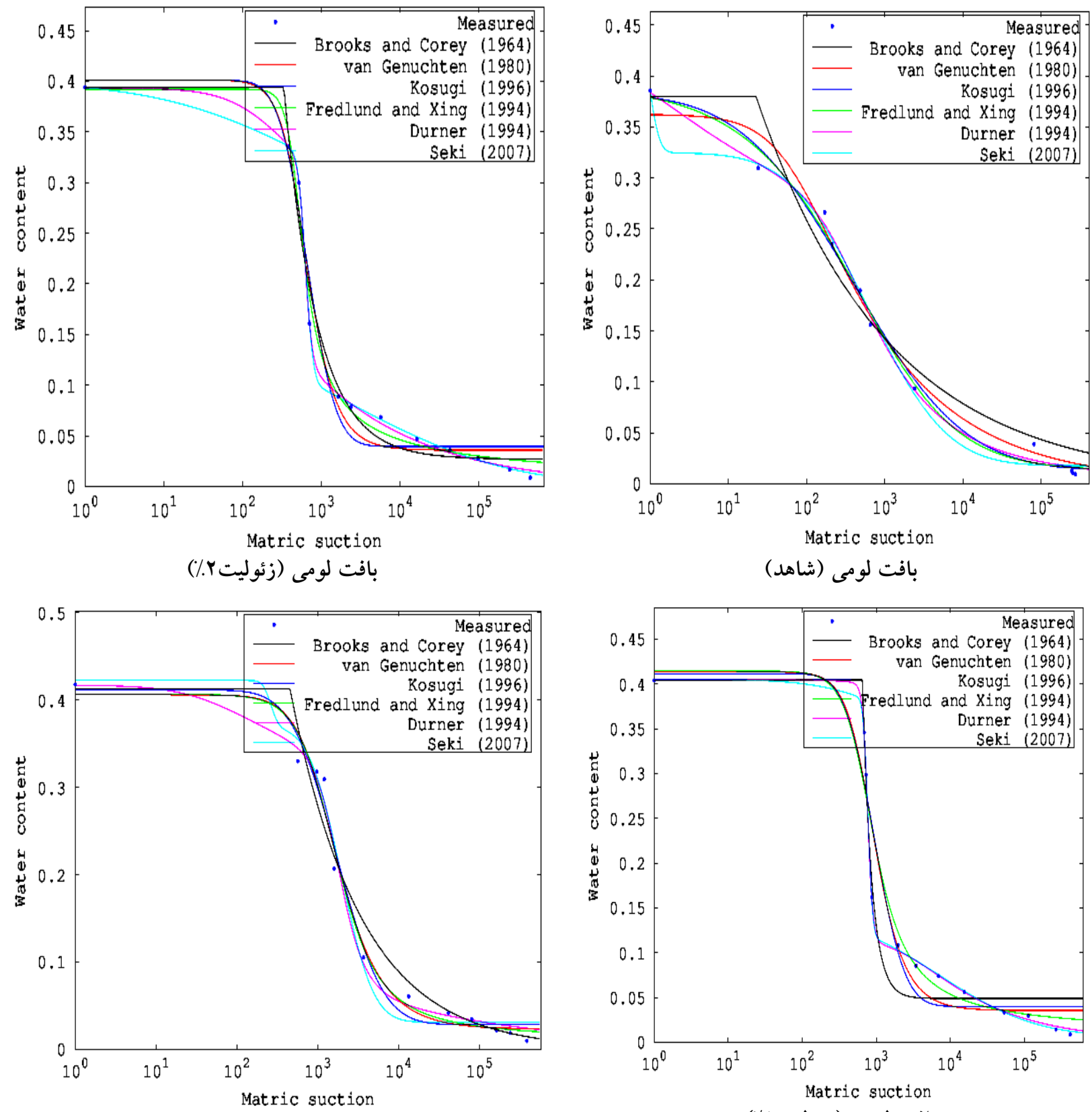

بافت لومى (شاهد)

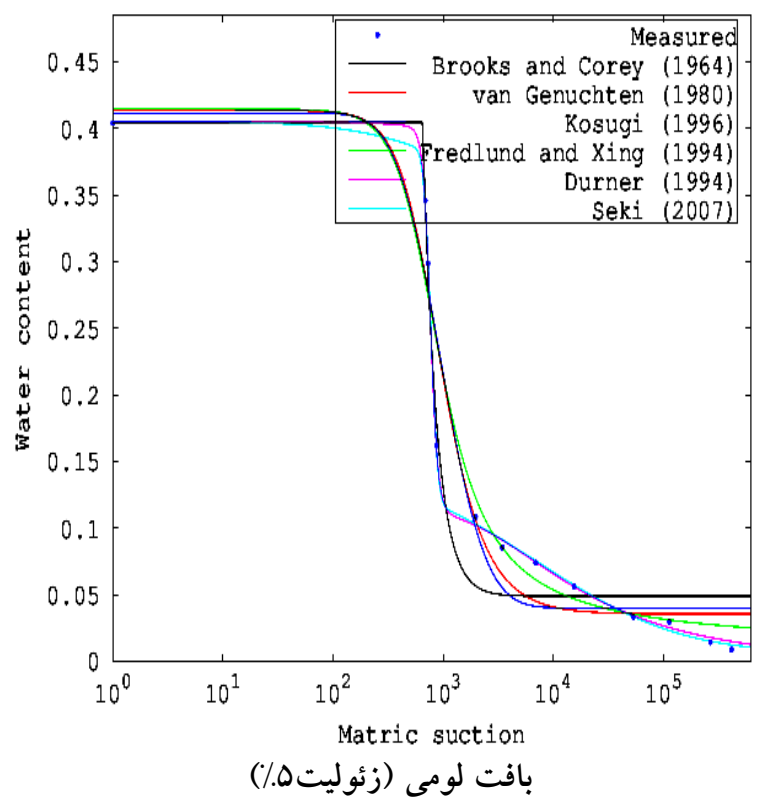

\section{شكل r. منحنى هاى رطوبتى خاك لومى با كاربرد زئوليت}

مقدار Os بهطور معنسى بـارى افـزايش يافـت ( نشاندهنده افزايش ظرفيـت نخهراشـت آب بـا وجــود زئوليـت در خاى است (شكل ل و ه). با توجه به اين نتايج مىتـوان بيـان كـرد كه كاربرد زئوليت در خاك شـنى در سـطح مصسرفهـاى مختلـف تأثير مثبت در ظرفيت نخهاشــت آب در خـاك دارد ولـى كـاربرد زئوليت در خاك لومى در سطح مصرفهاى كم (دو درصـد) تـأثير

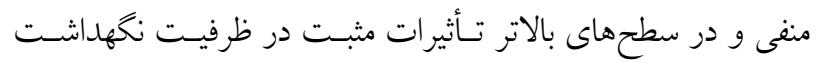

ظرفيت نخهارى آب در خاك است بنـابراين آزمـون والـيس و

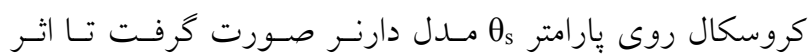
زئوليت بر ظرفيت نخهدارى آب در خاكهـا بررسىى شـود. بـا

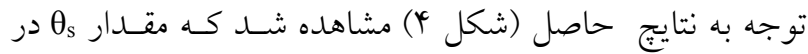

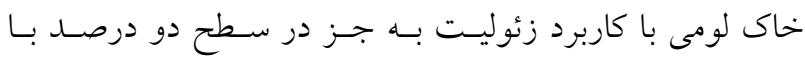
افزايش سطح مصرف بهطور معنى دارى افزايش يافت ( (1) در خاك شنى نيز با كاربرد زئوليـت و افـزايش سـطح اسـتفاده 
نشريه علوم آب و خاك (علوم و فنون كشاورزى و منابع طبيعى) / سال بيست و سه / شماره سوم / باييز \هسا
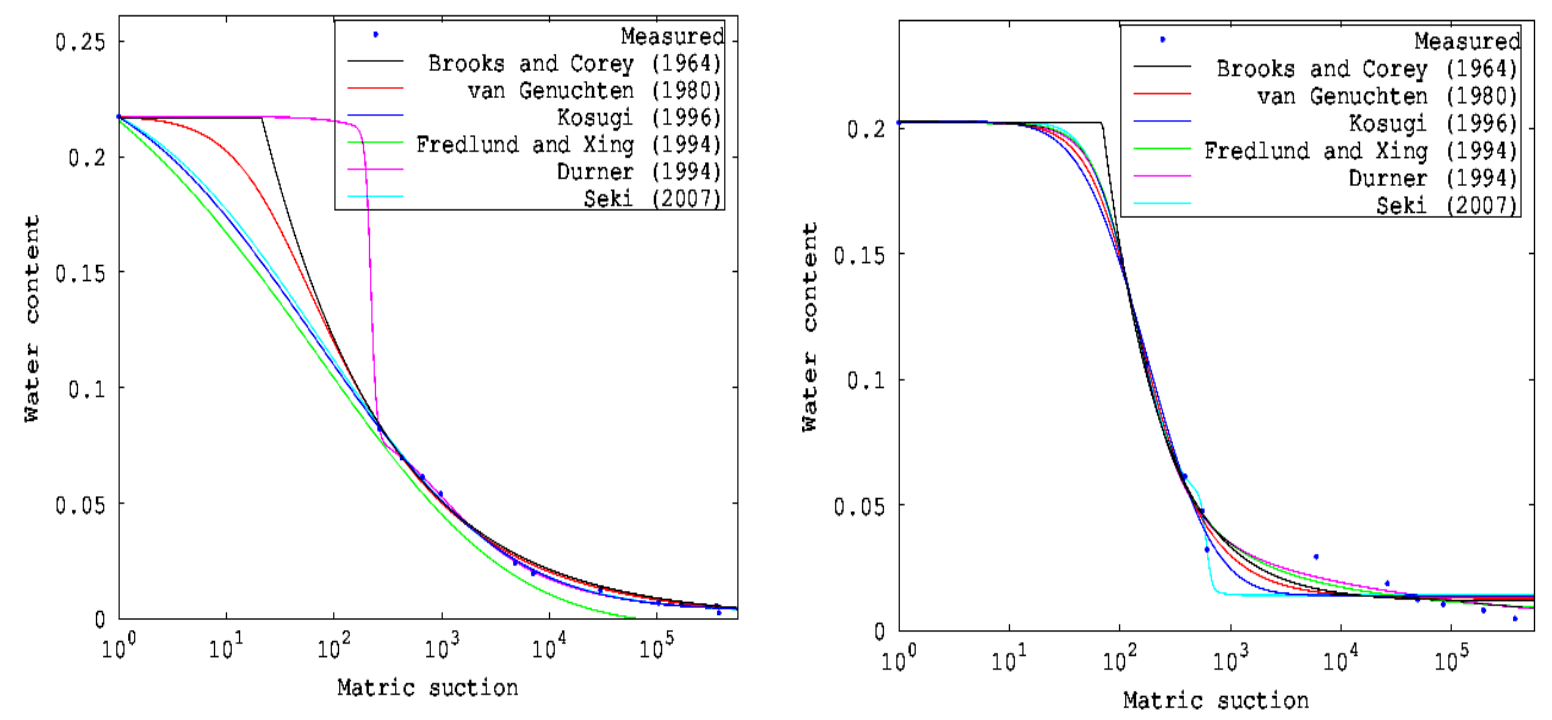

بافت شنى (زئوليتץ/\%)

بافت شنى (شاهد)
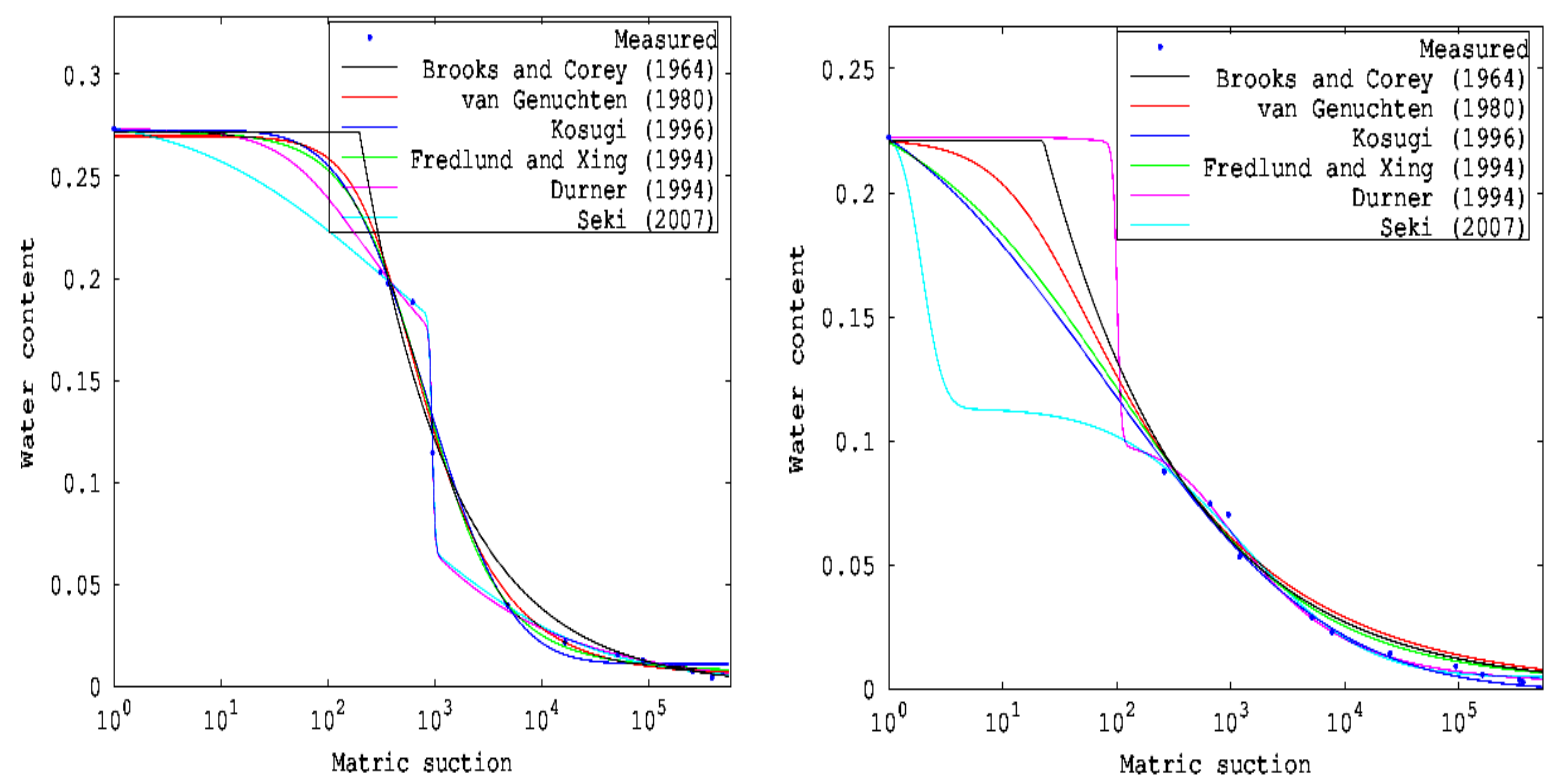

بافت شنى (زئوليت ا 1\%)

بافت شنى (زئوليتها/)

شكل r. منحنىهاى رطوبتى خاك شنى با كاربرد زئوليت

سويرجاذب زئوليت اين بارامتر نيز در هر دو بافت خاك و در تمـام

آب در خاك دارد.

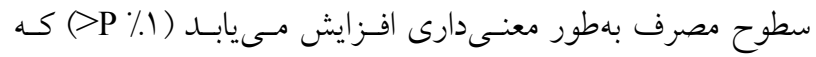

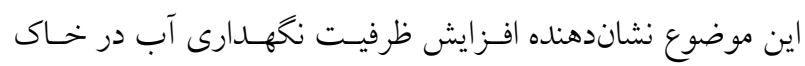

با وجود زئوليت در خاك است. اين نتايج با نتايج مطالعت ياسـودا

نتايج اين مطالعه نشان داد كه با افزودن زئوليت به هر دو نوع خـاك

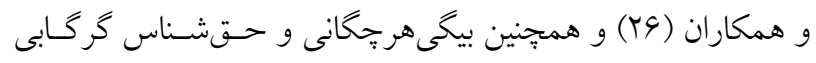
مورد مطالعه، يارامتر s در مناسبتــرين مــدل (مـدل دارنـر) داراى

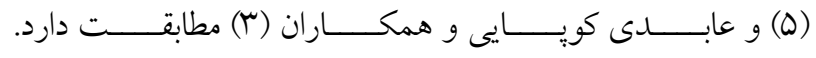

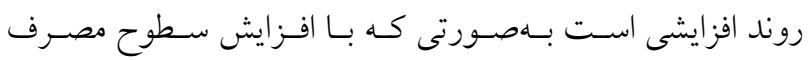




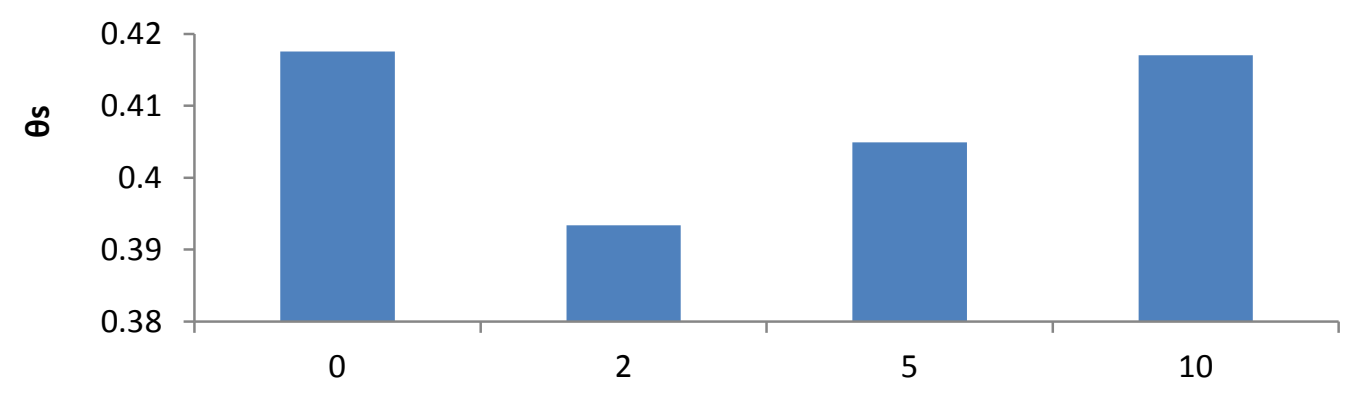

سطوح مصرف زئوليت (\%)

شكل †. تغييرات 0s در سطوح مختلف سويرجاذب در خاك لومى

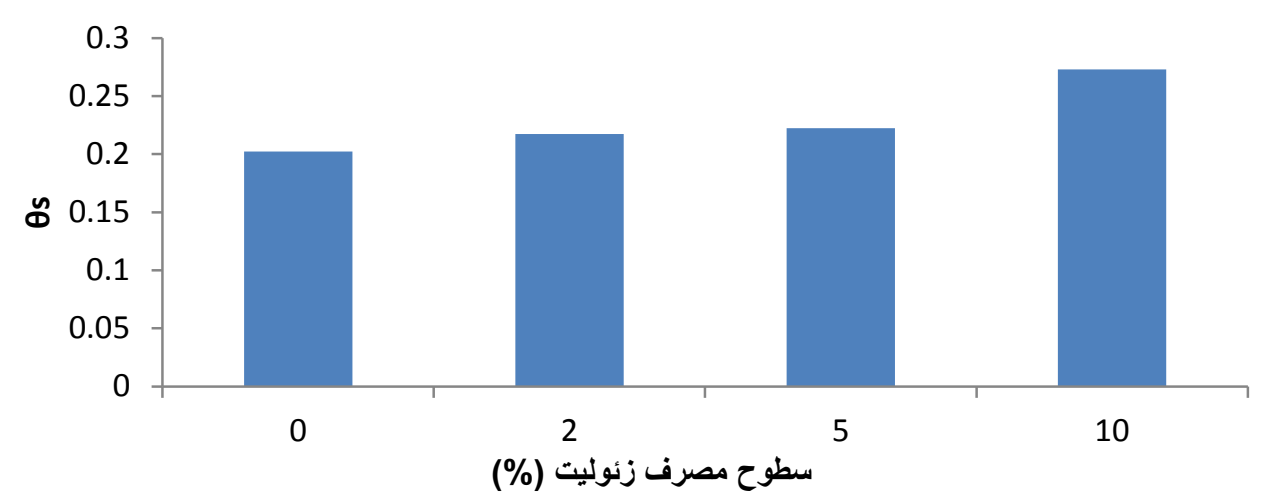

شكل ه. تغييرات Os در سطوح مختلف سويرجاذب در خاك شنى

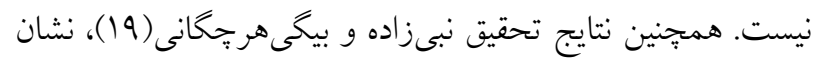

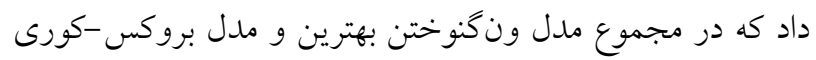
ضعيفترين مدل هستند.

\section{نتيجه گيرى}

بلهطور كلى نتايج اين يزوهش نشان داد كه افزودن سـويرجاذب

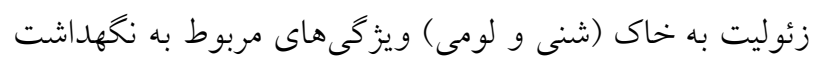

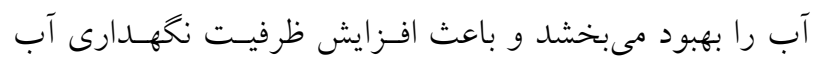

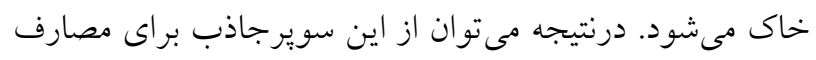

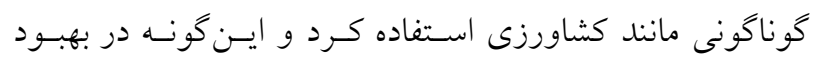

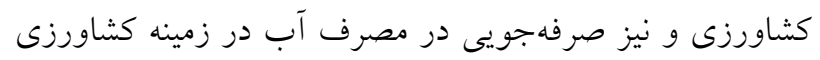

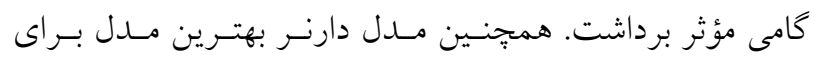
تخمين منحنى مشخصه رطسوبتى در خـاكهـاى لـومى و شسنى

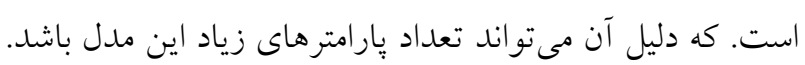

ياسودا و همكاران (TV) نيز طى مطالعهاى به ايسن نتيجـه رسـيدند

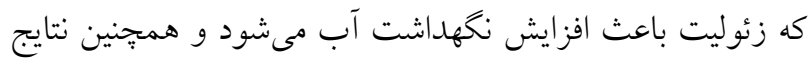

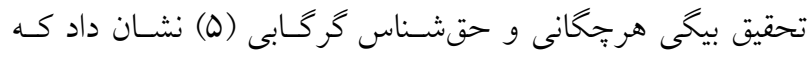

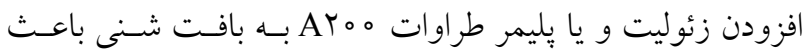

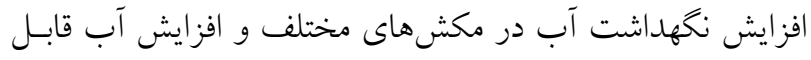

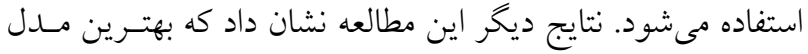
براى تخمين منحنى مشخصه رطوبتى خـاكهـاى لـومى و شـنى فئل

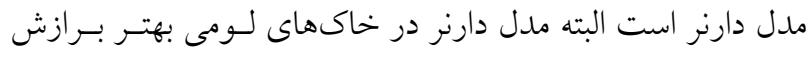

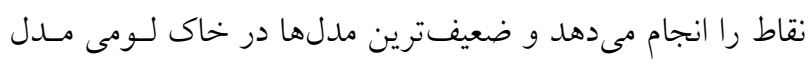

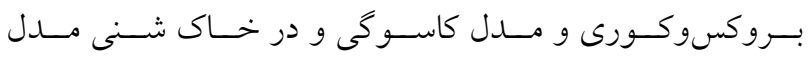
بروكسوكورى و مدل ونكنوختن هستند كه اين نتسايج بـا نتـايج

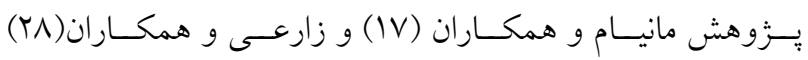

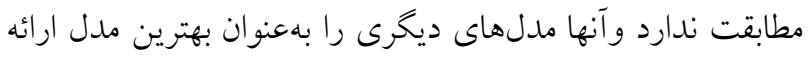

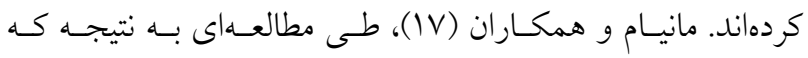

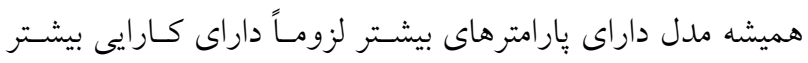


1. Abdi, GH. 2008. Effect of natural zeolite to reducing salt stress in Kentucky bluegrass (Poa pratensis). In: Proceeding of the $1^{\text {st }}$ Iran International Zeolite Conference, Tehran.

2. Asadkazemi, J. 2005. Effect of Superabsorbent A200 Polymer and Two Types of Firouzkouh and Semnan Zeolites on Growth Indicators and Water Requirement of Two Isfahan Green Landscape Plants. MSc. Thesis. Irrigation Field School of Agriculture. Isfahan University of Technology.

3. Abedi Koupai, J. and F. Sohrab. 2005. Estimation of Hydraulic Properties of Different Soils on Addition of Synthetic and Natural Superabsorbents Using RETC Model. Tehran, Third Specialized Training Course and Seminar on the Use of Superabsorbed Hydrogels.

4. Alemi, M. H. 1981. Water and Soil (translation). First Edition. University of Tehran Publications. No. 1792.

5. Begay Harchegani, H. and M. Haghshenas Gorgabe. 2012. Interaction effect of middle zeolite and refreshing polymer A200 on water retention capacity and coefficients of moisture curve model in a light soil texture. Iranian Journal of Rangeland and Desert Research19(4): 692-679.

6. Baiburdi, M. 2000. Principles of Irrigation Engineering. first volume. Water-soil relations. University of Tehran Publications. Seventh Edition.

7. Cornelis, W. M., J. Ronsyn, M. Van Meirvenne and R. Hartmann. 2001. Evaluation of pedotransfer functions for predicting the soil moisture retention curve. Soil Science Society of America Journal 65(3): 638-648.

8. Ebrahimi, A. S., H. Bayat, S. Sadeghi, M. Falah, M. Jere and M. Zanganeh. 2016. Application of Soil Density Curve Properties to Estimate Soil Moisture Using Van Genuchten Model. Iranian Journal of Soil and Water Research 47(2): 217-228

9. Ghayyur, F., Z. Eskandari and A. H. Sherbaf. 2005. Investigation and Comparison of Some Moisture Absorbents on Soil Water Retention and Potential. In: Proceedings of the $9^{\text {th }}$ Iranian Soil Science Congress, Karaj, pp. 293-295.

10. Ghanbarian, B., A. S. Lyagat, M. Shorafa and S. Moghimi. 2007. Evaluation of perfect fractal model in predicting soil moisture characteristic curve. Iranian Journal of Irrigation and Drainage 1(1): 7-19.

11. Haghshenas Gorgab, M. and H. Begay Harchegani. 2010. The effect of middle zeolite on water storage capacity and coefficients of moisture curve models of two sandy soil and lomersei textures. Iranian Journal of Water Research 4(6): $-42,35$.

12. He, X. and Z. Huang. 2001. Zeolite application for enhancing water infiltration and retention in loess soil. Conservation and Recycling 34(1): 45-52.

13. He, X. and Z. Huang. 2001. Zeolite application for enhancing water infiltration and retention in loess soil. Conservation and Recycling 34(1): 45-52.

14. Kheiri Shelmzari, K., S. Boroumandasnab, S. M. Alavi 2012. Effect of superabsorbent surfaces on saturated hydraulic conductivity, porosity and moisture characteristic curve in crop soil. In: Proceeding of the Third National Conference on Comprehensive Water Resources Management.

15. Kazemipour Esfahlan, 2011. Estimation of Soil Characteristic Curve Using Stability Limit and Some Physical Properties in Calcareous Soils. MSc. Thesis, Zanjan University, Faculty of Agriculture.

16. Liu, Y . B. and F. De Smet. 2004. WetSpa of Manual. Pp. 1-126.

17. Manyame, C., C. L. Morgan, J. L. Heilman, D. Fatondji, B. Gerad and W. A. Payne. 2007. Modeling hydraulic properties of sandy soils of Niger using pedotransfer functions. Geoderma 141: 407-415.

18. Naderi, F., A., Vashghani Farahani 2006. Soil moisture retention using water-absorbing polymers (hydrogels). Soil and Water Sciences 1(20): 64-72.

19. Nabizadeh, A. and H. Begay Harchegani. 2011. Fit quality of several experimental models of soil moisture curve in Lordegan city from Chaharmahal Bakhtiari province. Journal of Soil and Water Science and Technology 25(3): 634645.

20. Norafkan H. 2007. The Benefits of Stacosorb and Zeolite in Greenhouse Soil Blends. The first workshop to improve water use efficiency by cultivating greenhouse crops. Issue $18.9 \mathrm{p}$.

21. Rajurkar, M. P., U. C. Kothyari and C. C. Chaube. 2004. Modeling of the daily rainfall runoff relationship with artificial neural network. Journal of Hydrology 285: 96-113

22. Sohrab, F. 2003. Evaluation of the effect of addition of moisture absorbents on water retention capacity in ardestan watershed. MSc. Thesis, Department of Irrigation and Drainage, Faculty of Agriculture, Isfahan University of Technology.

23. Simunek, J., M. Th. VanGenuchten and M. Sejna. 2005. The HYDRUS-1D software package for simulating the one-dimensional movement of water, heat, and multiple solutes in variably- saturated media. Version 3.0, HYDRUS Software Series 1. Department of Environmental Sciences. University of California Riverside. Riverside. CA.

24. Torabi Farsani, N, B, Champion.2007. Gahreman of several conventional transfer functions for estimating soil moisture curve in multiple soils in Iran. Iranian Journal of Irrigation and Drainage 1(2): 45-57. 
25. Xiubin, H. and H. Zhandin. 2001. Zeolite application for enhancing water infiltration and retention in loess soil. Institute of Soil and Water Conservation, Chinese Academy 34: 45- 52.

26. Yasuda, H., K. Takuma, N. Mizuta and H. Nishide. 1995. Water retention variety of dune sand due to zeolite addition. Bulletin of the Faculty of Agriculture, Tottori University 48: 27-34 .

27. Yasuda H., K. Takuma, T. Fukuda, J. Suzuki and Y. Fukushima. 1998. Effects of zeolite amendment on water and salt characteristics in soil. In: Proceedings of the International Agricultural Engineering Conference, Bangkok. Thailand.

28. Zarei, G., M. Homayi and A. S. Leyagat. 2008. Estimation of unsteady evaporation from non-covered soil based on different soil moisture curve models. Iranian Journal of Irrigation and Drainage 2(2): 61-71. 


\title{
Investigating the Effect of Zeolite on the Coefficients of Soil Moisture Curve Models in Two Sandy and Loamy Texture
}

\author{
R. Ghazavi, E. Omidvar and H. Jeyhoni ${ }^{1 *}$
}

(Received: June 19-2017 ; Accepted: October 16-2018)

\begin{abstract}
One of the important elements in mechanized irrigation is to know the relation between suction force (matric force) and soil moisture, which is referred to as moisture curve. The shape and coefficients of this curve are influenced by the texture and structure of the soil and can change with soil structure modification. The most important goals of this study were to evaluate the effect of using zeolite on water holding capacity and coefficients of moisture curve patterns of two sandy and loamy soil texture, the effect of using zeolite on the shape and soil moisture curve coefficients based on various models, some of them so far in Iran, zeolite was added to soils at levels of consumption $(2,5$ and $10 \%)$. The moisture content of each soil was determined at various points in 12 points using a Dicagon machine. Soil moisture curve coefficients using software and fittings of six Brooks and Corey models, Kosugi, Durner, Fredlund and Xing, VanGenuchten and Seki. The results indicate that in all models, the parameter value increases with the use of zeolite and increase the level of use. Water storage capacity also increases with the use of zeolite. Other results showed that the best model for estimating the moisture curve of laryngeal and sandy soils of the Darren model is weakest and the weakest models in the lush soils of the broccoli model and Kasughi model and in the sandy soil of the Brooksouli model Blindness and model-gnuchten Shand.
\end{abstract}

Keywords: Zeolite, Soil moisture curve, Water storage in soil and SWRC 3.0

1. Department of Rangeland and Watershed Management, Faculty of Natural Resources and Earth Sciences, Kashan University, Kashan, Iran.

*: Corresponding Author, Email: hadiseh.jeyhoni@gmail.com 